LAWRENCE LIVERMORE N A TION AL LABORATORY
ETAII 6 MEV PEPPERPOT

EMITTANCE MEASUREMENT

A. C. Paul, R. Richardson, J. Weir

October 28, 2004 


\title{
ETAII 6 MEV PEPPERPOT EMITTANCE MEASUREMENT
}

\author{
Authur C. Paul, Roger Richardson, John Weir \\ June 29, 1998
}

This document was prepared as an account of work sponsored by an agency of the United States Government. Neither the United States Government nor the University of California nor any of their employees, makes any warranty, express or implied, or assumes any legal liability or

responsibility for the accuracy, completeness, or usefulness of any information, apparatus,

product, or process disclosed, or represents that its use would not infringe privately owned rights. Reference herein to any specific commercial product, process, or service by trade name, trademark, manufacturer, or otherwise, does not necessarily constitute or imply its endorsement, recommendation, or favoring by the United States Government or the University of California. The views and opinions of authors expressed herein do not necessarily state or reflect those of the United States Government or the University of California, and shall not be used for advertising or product endorsement purposes.

This work was performed under the auspices of the U.S. Department of Energy by University of California, Lawrence Livermore National Laboratory under Contract W-7405-Eng-48 


\title{
ETAII 6 MEV PEPPERPOT EMITTANCE MEASUREMENT
}

\author{
Arthur C. Paul, Roger Richardson, John Weir
}

June 29, 1998

We measured the beam emittance at the ETAII accelerator using a pepper-pot diagnostic at nominal parameters of $6 \mathrm{MeV}$ and 2000 Amperes. During the coarse of these experiments, a "new tune"1 was introduced which significantly improved the beam quality. The source of a background pedestal was investigated and eliminated. The measured "new tune" emittance is

$$
\varepsilon=8.05 \pm 0.53 \mathrm{~cm}-\mathrm{mr}
$$

or a normalized emittance of

$$
\varepsilon_{\mathrm{n}}=943 \pm 63 \mathrm{~mm}-\mathrm{mr}
$$

In 1990 the ETAII programmatic emphasis was on free electron lasers and the paramount parameter was whole beam brightness. The published brightness for ETAII after its first major rebuild ${ }^{2}$ was $\mathrm{J}=1-3 \times 10^{8} \mathrm{~A} /(\mathrm{m}-\mathrm{rad})^{2}$ at a current and energy of 1000-1400 Amperes and $2.5 \mathrm{MeV}$. The average normalized emittance derived from table 2 of that report is $864 \mathrm{~mm}$ - $\mathrm{mr}$ corresponding to a real emittance of $14.8 \mathrm{~cm}-\mathrm{mr}$.

\section{The Measurement}

The ETAII beam-line has been revised with the installation of two apertures to prevent ejecta (debris) from target experiments from projecting back into the accelerator. The installation of these apertures required the removal of the solenoid emittance selector and the first quadrupole doublet, q1-q2. This new beam line was further modified to accommodate the kicker hardware during target experiments and is referred to as "revision $0 \mathrm{~K}$ (zero $\mathrm{K})^{13}$ and is shown in figure 1 . The nominal beam parameters are given in table 1 and do not significantly differ from the parameters used in the original beam-line layout used in the 1988-1991 operations ${ }^{4}$. The parameters summarized in table 1 are for the "new tune". Figure 2, shows the nominal beam transport from the enterence of the last ten cell block to the pepper-pot emittance diagnostic.

Table 1

\begin{tabular}{|l|c|l|}
\hline Parameter & value & \multicolumn{1}{|c|}{ units } \\
\hline Energy & 5.5107 & $\mathrm{MeV}$ \\
momentum & 6.00 & $\mathrm{MeV} / \mathrm{c}$ \\
$\beta \gamma$ & 11.74 & \\
ridigity $\mathrm{B} \rho$ & 0.20014 & $\mathrm{kG}-$ meters \\
Emittance & 8.05 & $\mathrm{~cm}-\mathrm{mr}$ \\
Current & 2020 & $\mathrm{Amperes}$ \\
Cell6 & 0.7326 & $\mathrm{kG}$ \\
Radius & 0.837 & $\mathrm{~cm}$ \\
Tilt & 0 & $\mathrm{r}_{12}=0$ \\
\hline
\end{tabular}

\footnotetext{
${ }^{1}$ The new tune was introduced on 5/28/98, ETA day 8148 .

${ }^{2}$ IEEE 1991 Particle Accelerator Conference, May 6-9, 1991, San Francisco, California. ETA-II Beam Brightness Measurement, A.C.Paul, S.L.Allen, F.W.Chambers, Y-J Chen, F.J.Deadrick, W.C.Turner, page 3106-8.

${ }^{3}$ Bechtel Nevada drawing, EDG97-LSK14059, rev 0K, Initial ETA II beam-line

${ }^{4}$ ETAJR beam-line, Arthur C. Paul, RM88-43, August 26, 1988
} 
A pepper-pot emittance measuring diagnostic was installed past the kicker, after focusing solenoid EF5. The original distance between the mask and the viewing phosphor was 0.80 meters, with a mirror set at 45 degrees to the beam-line so that it could be viewed by a gated CCD camera system, figure 3 . During the pepper-pot measurements, the apertures at 1.277 meters and 6.490 meters were removed. The aperture at 1.277 meters was not installed until June 01 (ETA day 8152) and the aperture at 6.49 meters was not installed until June 09 (ETA day 8160).

\section{The Mask}

The machine was turned on with the copper mask used in the 20 cell (2.5 MeV) measurement ${ }^{5}$. The copper mask immediately melted. We next made a range thick carbon mask with hole size and spacings to accommodate a nominal $6 \mathrm{MeV}$ measurement ${ }^{6}$. From the 20 cell emittance measurement and the injector studies, we expected an emittance of $13 \mathrm{~cm}-\mathrm{mr}$. The trade off between hole size and spacing is to find as large an angular acceptance of the mask with out passed beamlet overlap of the view port while allowing the beamlets to expand sufficiently to obtain a reliable measure of the angular divergence at the mask. Table 2 shows some of the relevant values.

With a square array of holes spaced $0.7 \mathrm{~cm}$ apart, we could accommodate an 11 x 11 matrix of 121 holes in the nominal $14 \mathrm{~cm}$ diameter beam pipe. If the beam is tuned to a three $\mathrm{cm}$ radius, the angular divergence at a waist would be $4.33 \mathrm{mr}$ which is small compared to the angular acceptance of the holes considered here.

Table 2

\begin{tabular}{|l|c|c|c|c|}
\hline \hline $\begin{array}{c}\text { hole } \\
\text { diameter } \\
(\mathrm{cm})\end{array}$ & $\begin{array}{c}\text { drill } \\
\text { number }\end{array}$ & $\begin{array}{c}\text { angular } \\
\text { acceptance } \\
(\mathrm{mr})\end{array}$ & $\begin{array}{c}\text { beamlet } \\
\text { expansion } \\
\mathrm{r} / \mathrm{r}_{\mathrm{o}}\end{array}$ & $\begin{array}{c}\text { beamlet } \\
\text { radius } \\
(\mathrm{cm})\end{array}$ \\
\hline 0.396 & & 104 & Drift 1.0 meters & \\
0.1930 & 48 & 50.7 & 4.597 & 0.4436 \\
0.1321 & 55 & 35.0 & 6.632 & 0.438 \\
\hline & & & \multicolumn{3}{|c|}{ Drift 0.8 meters } \\
\hline 0.396 & & & 3.725 & 0.3596 \\
0.1930 & & & 5.340 & 0.353 \\
0.1321 & & & \multicolumn{3}{|c|}{ Drift 0.5 meters } \\
\hline & & & 2.456 & 0.237 \\
\hline 0.396 & & & 3.427 & 0.226 \\
0.1930 & & & & \multicolumn{3}{|c|}{} \\
0.1321 & & & & \\
\hline
\end{tabular}

The selection of a drift distance of 0.8 meters between the pepper-pot mask and the view foil was made on the basis of the beamlets just not overlapping on the view foil for these nominal parameters. Figure 3 shows the diagnostic layout. The separation between mask and view foil, along with the hole size and spacing were optimized to allow a wide range of beam phase space projections to be investigated. Figure 4 shows the nominal beam parameters as input to cell block six, transported to the mask with the final lens, EF5 tuned over a range to provide convergence, divergence, and match to the emittance diagnostic. The theoretical beam phase space expected from such a beam tuned onto this diagnostic is shown in figure 5 with the resulting expected X-Y view shown in figure 6. The $11 \mathrm{X} 11$ mask pattern is indicated. Note that we expect to be able to generate patterns of 1, 5, 9, ..., 69 beamlets over the tuning range provided by EF5 and the design layout geometry.

\footnotetext{
${ }^{5} 20$ Cell Emittance Measurement, ARM97-04

${ }^{6}$ The hole size, spacing, and layout are the same as used previously at ETA and ATA for similar measurement with similar nominal beam parameters.
} 


\section{Investigation of the Beam Pedestal}

The beam images appeared to consist of three distinct components: 1) a tilted plane background, 2) a cylindrical "pedestal", and 3) n distinct beamlets rising from the pedestal. The planar background was about 2-20 pixels in amplitude, the pedestal was about 50-70 pixels in amplitude, and the beamlets are 150-250 pixels in amplitude, all measured from the zero floor of the image. Table 3 summarizes our measurements in the quest of understanding the beam pedestal. This pedestal was first observed in the 20 cell emittance measurement performed after the 1997 rebuild. The total pixel count in the pedestal was a significant fraction of the total image pixel count, and so the pedestal could not be ignored. A typical image is shown in figure 7.

Figure 8 shows this image with the pixels "zeroed out" to their pedestal background local value. The result is the pedestal shown for two images, one with 74 beamlets and one with 29 beamlets, D8132M02 and D8132M04. Also shown, is a contour plot and electronically processed video image of the actual recorded data with a software subtraction of the beamlets.

Table 3

observed beam pedestal

\begin{tabular}{|c|c|c|c|c|c|c|}
\hline $\begin{array}{c}\text { Name } \\
\text { File } \\
* \text { RAS }\end{array}$ & $\begin{array}{c}\text { Number } \\
\text { of } \\
\text { beamlets }\end{array}$ & $\begin{array}{c}\text { Pedestal } \\
\text { Total } \\
\text { counts }\end{array}$ & $\begin{array}{c}\text { Pedestal } \\
\text { Peak }\end{array}$ & $\begin{array}{l}\text { Pedestal } \\
\text { Average }\end{array}$ & $\begin{array}{l}\text { Distance } \\
\text { Mask to } \\
\text { Phosphor }\end{array}$ & comment \\
\hline D8132M04 & 29 & $1.62 \times 10^{6}$ & 84 & 26.7 & 0.800 & Mask-Mirror 7" \\
\hline D8132M02 & 74 & $2.57 \times 10^{6}$ & 62 & 24.1 & 0.800 & \\
\hline D8139M04 & 23 & $1.05 \times 10^{6}$ & 63 & 32.7 & 0.564 & Shorten Drift \\
\hline D8140M02 & 35 & $1.21 \times 10^{6}$ & 62 & 17.3 & 0.109 & Saturated \\
\hline D8140M03 & 35 & $0.08 \times 10^{6}$ & 32 & 2.2 & $"$ & Reduce gain, no-sat \\
\hline D8140M05 & - & $0.36 \times 10^{6}$ & 59 & 22.6 & " & focus on mirror \\
\hline D8141M01 & 29 & $0.73 \times 10^{6}$ & 39 & 13.1 & 0.564 & Mask-Mirror 20" \\
\hline D8147M01 & 44 & $0.52 \times 10^{6}$ & 10 & 8.1 & 0.564 & Magnet between Mask-Mirror \\
\hline D8147M02 & 57 & $0.87 \times 10^{6}$ & 20 & 10.8 & $"$ & \\
\hline D8147M03 & 60 & $0.69 \times 10^{6}$ & 15 & 11.3 & $"$ & \\
\hline D8147M04 & 15 & $0.70 \times 10^{6}$ & 35 & 11.4 & $"$ & \\
\hline D8149M01 & 65 & $0.53 \times 10^{6}$ & - & 10.4 & 0.564 & Peak 15 (beamlet leakage) \\
\hline D8149M02 & 65 & $0.44 \times 10^{6}$ & - & 10.2 & $"$ & \\
\hline- & - & - & - & - & - & \\
\hline D8149M10 & 67 & & & & & \\
\hline
\end{tabular}

In the analysis, of the pepper-pot data, we subtract the planar tilted background from the image. We then analyze the beamlets above the local background, that is, the top of the pedestal. We next calculate the intensity of the pedestal by "zeroing" the beamlets to the amplitude of the local background as defined by the average of the sum of all pixels along the local boarder of the analysis window rectangle supperimposed over the beamlets "peak" amplitude. In this way, we obtained an emittance measurement in the presence of the pedestal.

What is (was) the pedestal. After many unsuccessful atemps to affect the amplitude of the pedestal, we found that it was nothing more than the electrons of the beamlets that scattered upon hitting the range thin viewing phosphor and continued to the viewing mirror. There the scattered electrons stimulated prompt photon emission from the front surface mirror. As the electrons had been scattered, their emittance was sufficient to cause complete and total overlapping of their images forming the pedestal. 
Upon understanding the source of the pedestal, its elimination was easy. We installed a dipole magnet between the viewing phosphor and the mirror. WALL-A - no pedestal.

\section{Identification of beamlets and Reconstructing the Beam Emittance}

The recorded image of the view foil is scanned by the IDL pepperpot code to identify objects to be taken as beamlets. An analysis window is defined by the user. The size of this window is approximately the spacing between the observed beamlets. Typically, this analysis window is 25 by 25 pixels for the ETAII images which are 384 by 576 pixels. An object will be considered a beamlet if 1) it has a peak amplitude larger than some given threshold, and 2) the object within the analysis window has more than 16 locations above that threshold. These two criteria are user adjustable and chosen to eliminate noise and spurious glitches in the image.

The center of objects identified as beamlets, along with the location of the bounding analysis window is saved for further analysis. Next, we determine the layout of holes through which these beamlets have passed on the mask. Once the mask hole pattern and image pattern have been determined, the geometry of the mask hole - image pattern is sufficient to reconstruct the beam phase space at the mask. The emittance is then calculated from the reconstructed phase space, as described in section "The analysis".

\section{The Old Tune}

Figure 9 shows a typical image and beamlet mask used in the reconstruction of the beam emittance for the old tune. The CCD image, figure 9A, is scanned to identify objects to be taken as beamlets. The center of these identified beamlets, along with the bounding analysis window is shown in figure 9D. The layout of holes through which these beamlets passed on the mask is shown in figure 9B. The geometry of the mask hole pattern, figure 9B and the image pattern figure 9D reconstructs the beam emittance at the mask. A profile cut through the image is shown in figure 9C. The pedestal is clearly visible. The relevant data is summarized in figure 10 for shot D8132M02. The reconstructed beam emittance is shown in figure 11. Table 4 gives the data for three measurements made with the kicker in the beam line and three measurements made with the kicker replaced by a plain pipe.

Table 4

Old Tune Emittance Values

\begin{tabular}{|c|c|c|c|c|}
\hline \hline $\begin{array}{c}\text { file } \\
\text { name }\end{array}$ & $\begin{array}{c}\text { number } \\
\text { beamlets }\end{array}$ & $\begin{array}{c}\text { pattern } \\
\text { nx X ny }\end{array}$ & $\begin{array}{c}\text { emitx } \\
\text { cm-mr }\end{array}$ & $\begin{array}{c}\text { emity } \\
\text { cm-mr }\end{array}$ \\
\hline $\mathrm{d} 8132 \mathrm{~m} 02$ & 74 & $9 \times 11$ & 11.36 & 13.25 \\
d8132m04 & 29 & $6 \times 7$ & 10.13 & 10.49 \\
d8132m06 & 23 & $5 \times 5$ & 9.53 & 9.01 \\
d8134m02 & 38 & $6 \times 7$ & 11.30 & 12.17 \\
d8134m04 & 37 & $7 \times 7$ & 11.36 & 12.43 \\
d8134m06 & $45(-5)$ & $7 \times 7$ & 12.45 & 12.48 \\
\hline
\end{tabular}

\section{The New Tune}

On 5/28/98, ETA day 8148, a new tune was dialed into the injector and accelerator. Figure 13 shows a typical image and beamlet mask used to reconstruct the beam phase space for the "new tune". Note how much sharper the CCD image is for the new tune compared to the old tune, figures 13 and 9. The analysis of the beamlet and mask patterns, figure 13B and 13D, give the beamlet expansions shiwn in figure 14. The reconstructed phase space at the mask and location of waist, is shown in figure 15 .

The size of the expanded beamlet at the view foil can be measured as a function of the peak amplitude of the image. For the new tune, the spacing between the mask and view foil was not large enough to see expansions for amplitude above 30 or 40 percent, figure 16. In subsequent experiments, we will 
increase the distance between the mask and view foil so as to obtain meaningful values of the emittance as a function of image amplitude.

The beam used to initiate the external beam transport calculation is taken as matched to the magnetic field of the last ten cell block of the accelerator, cell block 6 . The matched radius in this $0.7326 \mathrm{kG}$ field is determined by the beam emittance and space charge.

$$
\begin{aligned}
& \mathrm{r}_{\mathrm{i}}=0.6545 \mathrm{~cm} \\
& \mathrm{r}_{\varepsilon}=0.66114 \mathrm{~cm} \\
& \mathrm{r}=0.83723 \mathrm{~cm}
\end{aligned}
$$

where $r_{i}$ is the matched radius for a zero emittance beam, $r_{\varepsilon}$ is the matched radius for a zero current beam, and $r$ is the matched radius for a beam of combined emittance and current. The magnet field of the transport solenoids M80, EF0, EF1, etc. were adjusted to thread the beam through the beamline and transport it to the emittance measuring mask. This tune is given in table 5 and was shown in figure 4 with EF5 scanned over a range of 0 to $1.1 \mathrm{kG}$.

Table 5

D8149M*

\begin{tabular}{|l|c|c|c|}
\hline $\begin{array}{c}\text { Magnet } \\
\text { name }\end{array}$ & $\begin{array}{c}\text { length } \\
\text { (meters) }\end{array}$ & $\begin{array}{c}\text { field } \\
(\mathrm{kG})\end{array}$ & $\begin{array}{c}\text { current } \\
\text { (Amperes) }\end{array}$ \\
\hline Cell6 & - & 0.7326 & 122.1 \\
M80 & 0.200 & 0.9440 & 239.1 \\
EF0 & 0.224 & 0.8652 & 7.32 \\
EF1 & 0.224 & 0.7352 & 6.22 \\
EF2 & 0.224 & 0.3723 & 3.15 \\
EF3 & 0.224 & 0.6288 & 5.32 \\
EF4 & 0.224 & 0.0260 & 0.22 \\
C4A & 0.144 & 0.8756 & 165.0 \\
EF5 & 0.224 & 0.5299 & 4.40 \\
\hline
\end{tabular}

The solenoid focusing lens before the mask can be used to tune the beam for various conditions, converging, diverging, matched to a waist, etc.

Table 6

\begin{tabular}{|c|c|r|r|c|}
\hline $\begin{array}{c}\text { EF5 } \\
\mathrm{B}(\mathrm{kG})\end{array}$ & $\begin{array}{c}\text { radius } \\
(\mathrm{cm})\end{array}$ & tilt & $\begin{array}{c}\mathrm{r}^{\prime} \\
(\mathrm{mr})\end{array}$ & $\begin{array}{c}\text { number } \\
\text { beamlets }\end{array}$ \\
\hline 1.10 & 0.662 & 0.337 & 12.823 & 1 \\
1.00 & 0.935 & -0.035 & 8.561 & 5 \\
0.90 & 1.295 & 0.059 & 6.187 & 9 \\
0.80 & 1.660 & 0.472 & 5.466 & 21 \\
0.70 & 2.003 & 0.792 & 6.536 & 25 \\
0.60 & 2.312 & 0.913 & 8.265 & 37 \\
0.50 & 2.580 & 0.956 & 10.514 & 45 \\
0.40 & 2.803 & 0.973 & 12.367 & 49 \\
0.30 & 2.980 & 0.981 & 13.888 & 56 \\
0.20 & 3.107 & 0.985 & 15.009 & 69 \\
0.10 & 3.184 & 0.987 & 15.694 & 69 \\
0.00 & 3.209 & 0.988 & 15.923 & 69 \\
\hline
\end{tabular}

Assuming a uniform spatial density, we have the total current passed by the mask as 


$$
\mathrm{i}=\mathrm{I}_{\mathrm{o}} \mathrm{n} \frac{\pi \mathrm{r}_{\mathrm{h}}^{2}}{\pi \mathrm{R}^{2}}
$$

where $\mathrm{r}_{\mathrm{h}}$ is the hole radius, $\mathrm{R}$ the whole beam radius $\sqrt{\sigma_{11}}, \mathrm{I}_{\mathrm{o}}$ the impingant beam current, and $\mathrm{n}$ the number of beamlets. For $\# 55$ drill, the hole radius is $0.06604 \mathrm{~cm}$. Table 7 gives the current passed for a total impingant current of 2020 Amperes.

Table 7

\begin{tabular}{|c|c|c|c|}
\hline $\begin{array}{c}\text { EF5 } \\
\mathrm{B}(\mathrm{kG})\end{array}$ & $\begin{array}{c}\mathrm{R} \\
\text { radius } \\
(\mathrm{cm})\end{array}$ & $\begin{array}{c}\mathrm{n} \\
\text { number } \\
\text { beamlets }\end{array}$ & $\begin{array}{c}\mathrm{i} \\
\text { current } \\
\text { Amperes }\end{array}$ \\
\hline 1.10 & 0.662 & 1 & 20.1 \\
1.00 & 0.935 & 5 & 50.4 \\
0.90 & 1.295 & 9 & 47.3 \\
0.80 & 1.660 & 21 & 67.1 \\
0.70 & 2.003 & 25 & 55.1 \\
0.60 & 2.312 & 37 & 61.0 \\
0.50 & 2.580 & 45 & 59.6 \\
0.40 & 2.803 & 49 & 54.9 \\
0.30 & 2.980 & 56 & 55.5 \\
0.20 & 3.107 & 69 & 62.9 \\
\hline
\end{tabular}

Table 8 give the result of ten shots under identical conditions, images D9148M01 .. M10. These values are plotted in figure 17 where three lines are shown for a plot of the horizontal values, the vertical values, and the average of the horizontal and vertical values. The average of these ten measurements is

$$
\varepsilon=8.05 \pm 0.53 \mathrm{~cm}-\mathrm{mr}
$$

Table 8

New Tune Emittance Measurements

\begin{tabular}{|c|c|c|c|c|c|c|}
\hline \hline $\begin{array}{c}\text { file } \\
\text { name }\end{array}$ & $\begin{array}{c}\text { number } \\
\text { beamlets }\end{array}$ & $\begin{array}{c}\text { pattern } \\
\text { nx X ny }\end{array}$ & $\begin{array}{c}\text { horizontal } \\
\text { emittance } \\
\text { cm-mr }\end{array}$ & $\begin{array}{c}\text { vertical } \\
\text { emittance } \\
\text { cm-mr }\end{array}$ & $\begin{array}{c}\text { average } \\
\text { emittance } \\
\text { cm-mr }\end{array}$ & $\begin{array}{c}\text { normalized } \\
\text { emittance } \\
\text { mm-mr }\end{array}$ \\
\hline d8149m01 & 61 & $9 \times 9$ & 7.484 & 7.653 & 7.569 & 887.1 \\
d8149m02 & 69 & $9 \times 9$ & 8.068 & 9.372 & 8.720 & 1022 \\
d8149m03 & 67 & $9 \times 9$ & 7.259 & 9.109 & 8.184 & 959.2 \\
d8149m04 & 70 & $9 \times 9$ & 7.930 & 7.630 & 7.780 & 911.8 \\
d8149m05 & 66 & $9 \times 9$ & 6.987 & 8.083 & 7.535 & 883.1 \\
d8149m06 & 67 & $9 \times 9$ & 8.591 & 8.130 & 8.361 & 979.9 \\
d8149m07 & 71 & $9 \times 9$ & 8.662 & 7.919 & 8.290 & 971.6 \\
d8149m08 & 65 & $9 \times 9$ & 7.661 & 8.185 & 7.923 & 928.6 \\
d8149m09 & 68 & $9 \times 9$ & 8.234 & 7.873 & 8.053 & 943.9 \\
d8149m10 & 69 & $9 x 9$ & 8.628 & 7.638 & 8.133 & 953.3 \\
& & & & & & \\
d8149m11 & 55 & $9 x 9$ & 5.953 & 6.502 & 6.227 & 729.8 \\
d8149m12 & 23 & $6 \times 6$ & 4.312 & 5.069 & 4.690 & 549.7 \\
d8149m13 & 15 & $4 \times 4$ & 7.281 & 9.856 & 8.568 & 1004.3 \\
\hline
\end{tabular}

\section{Effect of the Bucking Coil}

ETAII has two coils bracketting the cathode. These coils are excited so as to buck out the magnetic field from the injector focusing solenoids in the anode stock. Failure to minimize the field on the cathode, 
will result in a beam that is rotating once extracted from the accelerator. This rotation manifest itself as an effective increase in the beam emittance. The excitation of bucking coil two was changed by \pm 5 Amperes about the normal setting. The measured emittance increased for both perturbations, indicating that the normal setting indeed produces a minimum emittance and hence, minimum field on the cathode. Figure 18 shows the emittance vs bucking coil current.

Table 9

Effect of Bucking Coil on Emittance

\begin{tabular}{|c|c|c|c|c|c|c|}
\hline \hline $\begin{array}{c}\text { file } \\
\text { name }\end{array}$ & $\begin{array}{c}\text { number } \\
\text { beamlets }\end{array}$ & $\begin{array}{c}\text { pattern } \\
\text { nx X ny }\end{array}$ & $\begin{array}{c}\text { horizontal } \\
\text { emittance } \\
\text { cm-mr }\end{array}$ & $\begin{array}{c}\text { vertical } \\
\text { emittance } \\
\text { cm-mr }\end{array}$ & $\begin{array}{c}\text { average } \\
\text { emittance } \\
\text { cm-mr }\end{array}$ & $\begin{array}{c}\text { normalized } \\
\text { emittance } \\
\text { mm-mr }\end{array}$ \\
\hline $\mathrm{d} 8149 \mathrm{~m} 14$ & 87 & $10 \times 11$ & 9.642 & 11.457 & 10.549 & 1236.4 \\
$\mathrm{~d} 8149 \mathrm{~m} 15$ & 87 & $10 \times 11$ & 8.510 & 10.047 & 9.279 & 1087.5 \\
$\mathrm{~d} 8149 \mathrm{~m} 16$ & 87 & $10 x 11$ & 11.433 & 11.787 & 11.610 & - \\
\hline
\end{tabular}

\section{The Results of 199720 Cell Emittance Measurements}

A pepper-pot mask and image phosphor was installed after the second ten cell block to make a comparison with the measurements made at ETA in 1990. The mask consisted of a round set of $0.0568 \mathrm{~cm}$ diameter holes spaced on a radial $0.711 \mathrm{~cm}$ increment. The mask was range thick with thickness $0.322 \mathrm{~cm}$. The hole layout consist of a central hole surrounded by rings of 8,16,16,16 and 32 holes each. The image phosphor was 0.8685 meters beyond the mask. The beam current was approximently 1400 Amperes at 2.55 $\mathrm{MeV}$. Note: no attempt was made to minimize the corkscrew or BBU. This was a gee whiz lets look and see experiment. Those involved knew that when we really tune the machine, we will do a lot better than the result here reported.

Four different beam tunes were used to image the beam on the mask to produce a center hole plus two rings, plus three rings, plus four rings, and a uniform illumination. Files R7056F09 and R7057F07 partially illuminated the fourth and fifth mask rings respectively. File R7057F05 illuminated only the first and second ring. The beam in this file might just filled ring two, or it might just failed to illuminate ring three. This leads to an uncertainty of $3 / 2$ in the observed value of $16.90 \mathrm{~cm}-\mathrm{mr}$, table 9 , column $\delta \varepsilon$.

Note, that all four images appear rotated. A magnetic field threading the injector cathode leads to this rotation and results in an increase in angular spread. This systematic off set of the beamlets could be removed by rotating the mask by -3.0 degrees. The resulting horizontal and vertical emittance then become equal.

Table 9

Emittance with -3 degree Mask rotation.

\begin{tabular}{|c|c|c|c|c|c|c|}
\hline $\begin{array}{c}\text { File } \\
\text { *.RAS }\end{array}$ & $\begin{array}{c}\text { Number } \\
\text { of rings }\end{array}$ & $\begin{array}{c}\text { Number } \\
\text { of beamlets }\end{array}$ & $\begin{array}{c}\varepsilon_{\mathrm{x}} \\
\mathrm{cm}-\mathrm{mr}\end{array}$ & $\begin{array}{c}\varepsilon_{\mathrm{y}} \\
\mathrm{cm}-\mathrm{mr}\end{array}$ & $\begin{array}{c}\varepsilon \text { (ave) } \\
\mathrm{cm}-\mathrm{mr}\end{array}$ & $\begin{array}{c}\delta \varepsilon \\
\mathrm{cm}-\mathrm{mr}\end{array}$ \\
\hline R7056F09 & 5 & 61 & 24.03 & 24.67 & 24.35 & - \\
R7057F05 & 2 & 24 & 17.35 & 16.46 & 16.90 & 8.45 \\
R7057F06 & 3 & 40 & 19.83 & 19.07 & 19.45 & 6.27 \\
R7057F07 & 4 & 50 & 22.09 & 21.99 & 22.04 & - \\
\hline
\end{tabular}

The average $\varepsilon_{\mathrm{x}}, \varepsilon_{\mathrm{y}}$ for all four tunes is

$$
\bar{\varepsilon}=20.68 \mathrm{~cm}-\mathrm{mr}
$$

which corresponds to a normalized emittance of

$$
\bar{\varepsilon}_{\mathrm{n}}=1222 \mathrm{~cm}-\mathrm{mr}
$$

and a ARM experimental full energy 6.3 MeV emittance of 


$$
\varepsilon=9.19 \mathrm{~cm}-\mathrm{mr}
$$

\section{Comparison Between 20 Cell Measurements}

A pepper-pot mask and image phosphor was installed after the second ten cell block of the accelerator to make a comparison with the measurements made on ETA in $1990^{7}$ at that same location. In the fall of 1990, ETAII underwent a major pulse power upgrade, resuming operation with the injector and first two ten cell accelerating blocks. The nominal electron beam parameters were 1500 Amperes, 2.5 MeV. The beam brightness diagnostic consisted of a Cherenkov foil view port and a pepper-pot emittance diagnostic. The published values ${ }^{8}$ are The 1990 emittance measurements were performed after careful tuning of the injector and accelerator. The reported normalized emittance (inferred from the data of table 2 of the report) compare with our "new tune" emittance and is only 30\% smaller than the 1997 - don't tune - just turn on and measure - value:

\begin{tabular}{ccrc} 
& data & $\varepsilon_{\text {n }}$ & units \\
\hline & 1990 & 864 & mm-mr \\
& 1997 & 1222 & mm-mr \\
June & 1998 & 943 & mm-mr
\end{tabular}

\section{The Analysis}

Let $\mathrm{h}$ be the mask hole radius and $\mathrm{R}$ the impingant beam radius. The horizontal and vertical emittance $\varepsilon_{\mathrm{x}}$ and $\varepsilon_{\mathrm{y}}$ of beamlet $\mathrm{n}$ at the mask is given by

$$
\begin{aligned}
& \varepsilon_{x}(n)=\frac{h\left[r_{x}(n)-h\right]}{D} \\
& \varepsilon_{y}(n)=\frac{h\left[r_{y}(n)-h\right]}{D}
\end{aligned}
$$

where $r_{x}(n)$ and $r_{y}(n)$ are the $x$ and $y$ radius of beamlet $n$ at the location of the CCD image and D is the distance between the mask and the CCD image. The phase space at the mask for a given beamlet is upright, i.e., a beamlet is at a waist although the impingant beam is not (could be, but probably not).

The beam current associated with each beamlet is calculated from the total beam current $\mathrm{I}_{\mathrm{t}}$. If the beam is uniformly dense, then the total current passed through the mask $\mathrm{I}_{\mathrm{m}}$ is given by

$$
\mathrm{I}_{\mathrm{m}}=\mathrm{I}_{\mathrm{t}} \mathrm{N}\left(\frac{\mathrm{h}}{\mathrm{R}}\right)^{2}
$$

where $\mathrm{N}$ is the total number of beamlets. The current passed by the mask can alternatively be given as an input parameter to the pepperpot code. The current carried by each beamlet is weighted by its relative intensity. Let $\mathrm{p}_{\mathrm{n}}$ be the image pixels associated with beamlet $\mathrm{n}$ and let $\mathrm{P}_{\mathrm{t}}$ be the total of pixels associated with the entire image. The beam current $i_{n}$ carried by beamlet $n$ is then taken as

$$
\mathrm{i}_{\mathrm{n}}=\mathrm{I}_{\mathrm{m}} \frac{\mathrm{p}_{\mathrm{n}}}{\mathrm{P}_{\mathrm{t}}} \quad \text { where } \mathrm{P}_{\mathrm{t}}=\sum_{1}^{\mathrm{N}} \mathrm{p}_{\mathrm{n}}
$$

\footnotetext{
7 already cited

${ }^{8}$ IEEE 1991 Particle Accelerator Conference, May 6-9, 1991, San Francisco, California. ETA-II Beam Brightness Measurement, A.C.Paul, S.L.Allen, F.W.Chambers, Y-J Chen, F.J.Deadrick, W.C.Turner, page 3106-8.
} 
The beam brightness $j_{n}$ of beamlet $n$ is calculated as

$$
\mathrm{j}_{\mathrm{n}}=\frac{2 \mathrm{i}_{\mathrm{n}}}{[\pi \beta \gamma \varepsilon(\mathrm{n})]^{2}}
$$

where $\varepsilon(\mathrm{n})$ is the emittance of the nth beamlet. Calculation of the whole beam parameters follows from the Lapostole ${ }^{9}$ end Emigh ${ }^{10}$ method, where

$$
\begin{aligned}
& \varepsilon_{\mathrm{x}}^{2}=\left\langle\mathrm{x}_{\mathrm{n}}^{2}\right\rangle\left\langle\mathrm{x}_{\mathrm{n}}^{\prime 2}\right\rangle-\left\langle\mathrm{x}_{\mathrm{n}} \mathrm{x}_{\mathrm{n}}^{\prime}\right\rangle^{2} \\
& \varepsilon_{\mathrm{y}}^{2}=\left\langle\mathrm{y}_{\mathrm{n}}^{2}\right\rangle\left\langle\mathrm{y}_{\mathrm{n}}^{\prime 2}\right\rangle-\left\langle\mathrm{y}_{\mathrm{n}} \mathrm{y}_{\mathrm{n}}^{\prime}\right\rangle^{2}
\end{aligned}
$$

The whole beam brightness $\mathrm{J}$ is then given by

$$
\mathrm{J}=\frac{2 \mathrm{I}_{\mathrm{t}}}{(\pi \varepsilon \beta \gamma)^{2}}
$$

where $\varepsilon$ is the average of $\varepsilon_{\mathrm{x}}$ and $\varepsilon_{\mathrm{y}}$. In TRANSPORT sigma matrix formalism we have

$$
\varepsilon^{2}=\operatorname{det} \sigma
$$

where

$$
\begin{gathered}
\sigma_{11}=\frac{4}{\mathrm{~N}} \sum_{1}^{\mathrm{N}} \mathrm{x}_{\mathrm{n}}^{2} \\
\sigma_{21}=\frac{4}{\mathrm{~N}} \sum_{1}^{\mathrm{N}} \mathrm{x}_{\mathrm{n}} \mathrm{x}_{\mathrm{n}}^{\prime} \\
\sigma_{22}=\frac{4}{\mathrm{~N}} \sum_{1}^{\mathrm{N}} \mathrm{x}_{\mathrm{n}}^{22} \\
\sigma_{33}=\frac{4}{\mathrm{~N}} \sum_{1}^{\mathrm{N}} \mathrm{y}_{\mathrm{n}}^{2} \\
\sigma_{43}=\frac{4}{\mathrm{~N}} \sum_{1}^{\mathrm{N}} \mathrm{y}_{\mathrm{n}} \mathrm{y}_{\mathrm{n}}^{\prime} \\
\sigma_{44}=\frac{4}{\mathrm{~N}} \sum_{1}^{\mathrm{N}} \mathrm{y}_{\mathrm{n}}^{22}
\end{gathered}
$$

Each point of beamlet $n$, is simply the extremal values of the $n$th beamlet and $\left\langle x_{n}^{2}>\right.$ is the average value of the sum of $x_{n}$ square taken over the $n$ beamlets.

$$
\mathrm{x}=\sqrt{\sigma_{11}}=\max (\operatorname{abs}(\operatorname{phase}(*, 0)))
$$

\footnotetext{
${ }^{9}$ P.M.Lapostole, IEEE Trans. Nucl. Sci. NS-18, No. 3, 1101 (1971)

${ }^{10}$ C.Robert Emigh, "Statistical Beam Transport for High Intensity Ion Current", Proceedings of the 1972 Proton Linear Accelerator Conference, October 10-13, 1972, Los Alamos, New Mexico, LA-5115(UC-28), page 182 .
} 


$$
\begin{aligned}
& \mathrm{x}^{\prime}=\sqrt{\sigma_{22}}=\max (\operatorname{abs}(\operatorname{phase}(*, 1))) \\
& \mathrm{y}=\sqrt{\sigma_{33}}=\max (\operatorname{abs}(\operatorname{phase}(*, 3))) \\
& \mathrm{y}^{\prime}=\sqrt{\sigma_{44}}=\max (\operatorname{abs}(\operatorname{phase}(*, 4)))
\end{aligned}
$$

$\sigma_{21}$ is determined from the whole beam emittance, and the values of $\mathrm{x}$ and $\mathrm{x}^{\prime}$.

$$
\sigma_{21}=\sqrt{\sigma_{11} \sigma_{22}-\varepsilon_{\mathrm{x}}^{2}}
$$

and similarly for $\sigma_{43}$. The normalized beam tilts, $\mathrm{r}_{12}$ and $\mathrm{r}_{34}$ are defined by

$$
\begin{aligned}
& \mathrm{r}_{12} \equiv \frac{\sigma_{21}}{\sqrt{\sigma_{11} \sigma_{22}}} \\
& \mathrm{r}_{34} \equiv \frac{\sigma_{43}}{\sqrt{\sigma_{33} \sigma_{44}}}
\end{aligned}
$$

The value of the phase $\left.{ }^{*}\right)$ array can be listed by the pepperpot code 1)ist command. 
FIGURE 1 Layout of the magnets from the ETA accelerator to the pepper-pot mask and viewing phosphor. The origin of the longitudinal coordinate is taken at the exit of the accelerator.

FIGURE 2 Nominal beam transport from the start of the last ten cell block of the accelerator to the pepper-pot emittance diagnostic. The magnets are set of the experimental conditions of the "new tune".

FIGURE 3 Major components of the pepper pot emittance diagnostic. A range thick mask, a phosphor viewing foil, mirror and gated CCD camera.

FIGURE 4 Beam profile calculated for the "New Tune" experimental magnet settings leading up to the emittance mask. The last focusing magnet EF5 is scanned in strength.

FIGURE 5 Phase space at the location of the emittance mask for the magnet settings of ETA day 8149 with EF5 scan in $0.1 \mathrm{kG}$ steps between zero and $1.1 \mathrm{kG}$.

FIGURE 6 Calculated beam spot on the emittance mask for magnet settings used in figures 3 and 4 with the final lens EF5 scanned in $0.1 \mathrm{kG}$ steps.

FIGURE 7 Typical emittance image for the "old tune" at nominal parameters of 6.0 MeV, 1800 Amperes. The $10 \mathrm{nsec}$ gated tv image, contour plot and surface plot for shot D8132M04.

FIGURE 8 Shot D8132M04 with the 29 beamlets subtracted in software from the actual image. The result is the "pedestal". Also shown is shot D8132M02 with 74 beamlets subtracted.

FIGURE 9 Typical image and beamlet mask used in the reconstruction of the beam emittance for the old tune.

FIGURE 10 Old tune analysis for shot D8132M02. The beamlets expand from 0.066 $\mathrm{cm}$ to an average of $0.199 \mathrm{~cm}$ in the 0.8 meter drift. This gives an average angular value of $3.34 \mathrm{mr}$.

FIGURE 11 Reconstructed old tune phase space at the location of the mask and transformed to the location of the waist.

FIGURE 12 Reconstructed emittance vs amplitude.

FIGURE 13 Typical image and beamlet mask used in the reconstrcution of the beam emittance for the new tune data.

FIGURE 14 New tune analysis for shot D8149M04. The beamlets expand from 0.066 $\mathrm{cm}$ to an average of $0.118 \mathrm{~cm}$ in the 0.564 meter drift. This gives an average beam divergence of $1.83 \mathrm{mr}$.

FIGURE 15 Reconstructed new tune phase space at the location of the mask and 
transformed to the location of the waist.

FIGURE 16 Reconstructed emittance vs amplitude. The new tune emittance was sufficiently better than the old tune that the higher percent levels do not render an measure of the beamlet expansion. This will be remedied by increasing the distance between the mask and view foil.

FIGURE 17 Comparison between the various measurements of the old and new tunes.

FIGURE 18 Effect of the bucking coil. 


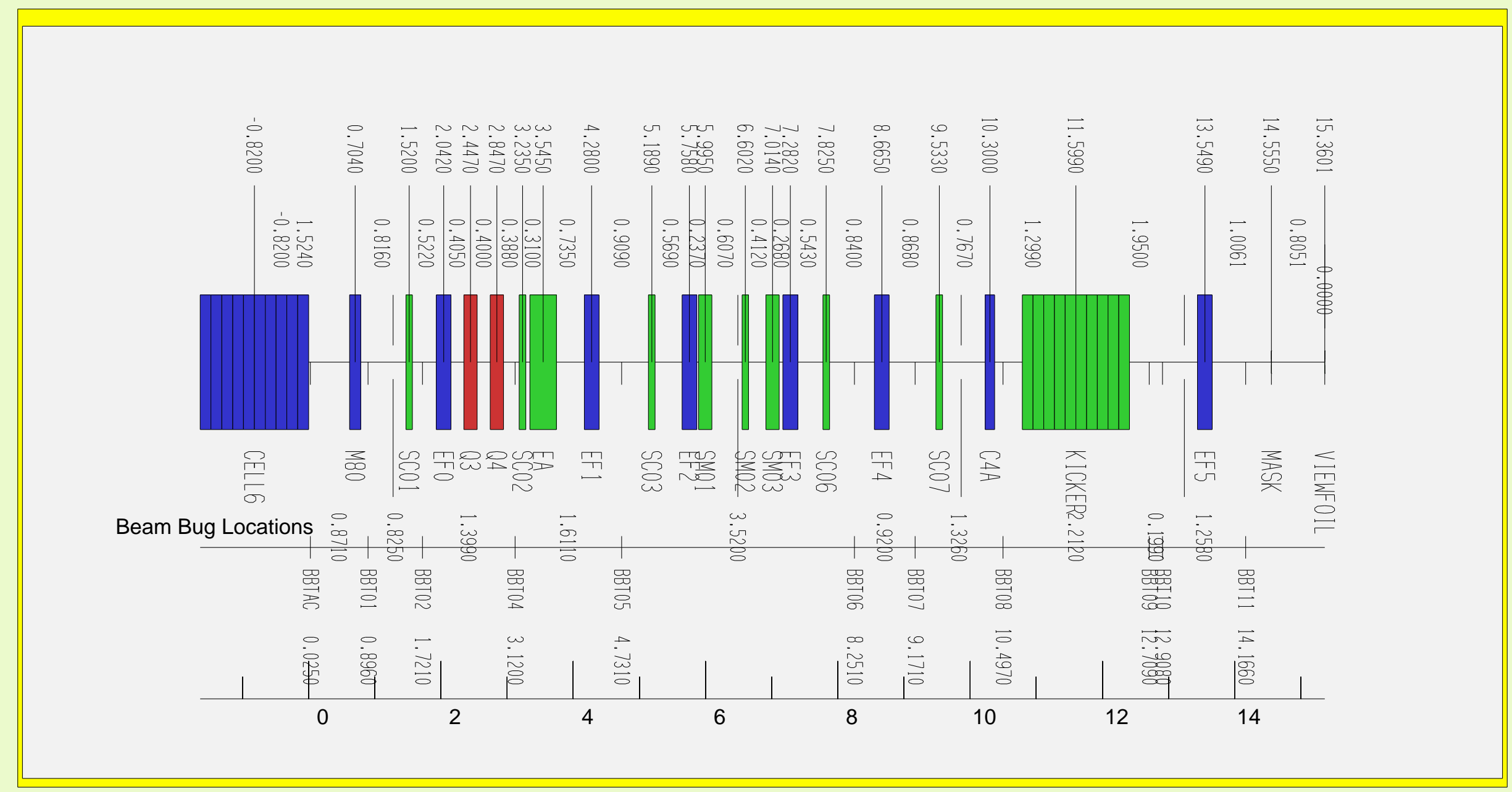

FIGURE 1

Layout of the magnets from the ETA accelerator to the pepper-pot mask and viewing phosphor. The origin of the longitudinal coordinate is taken at the exit of the accelerator. 

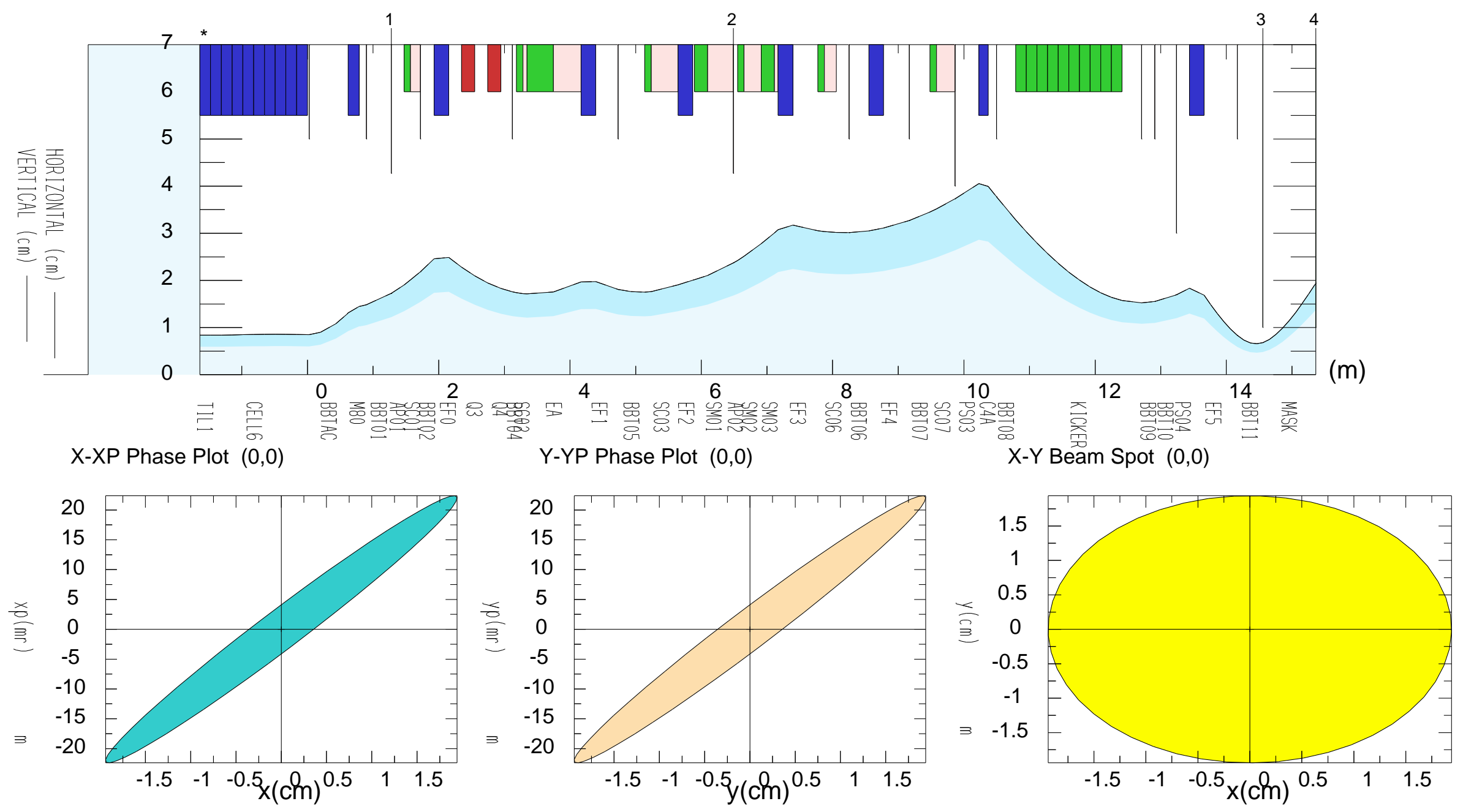

FIGURE 2

Nominal beam transport from the start of the last ten cell block of the accelerator to the pepper-pot emittance diagnostic. The magnets are set of the experimental conditions of the "new tune". 


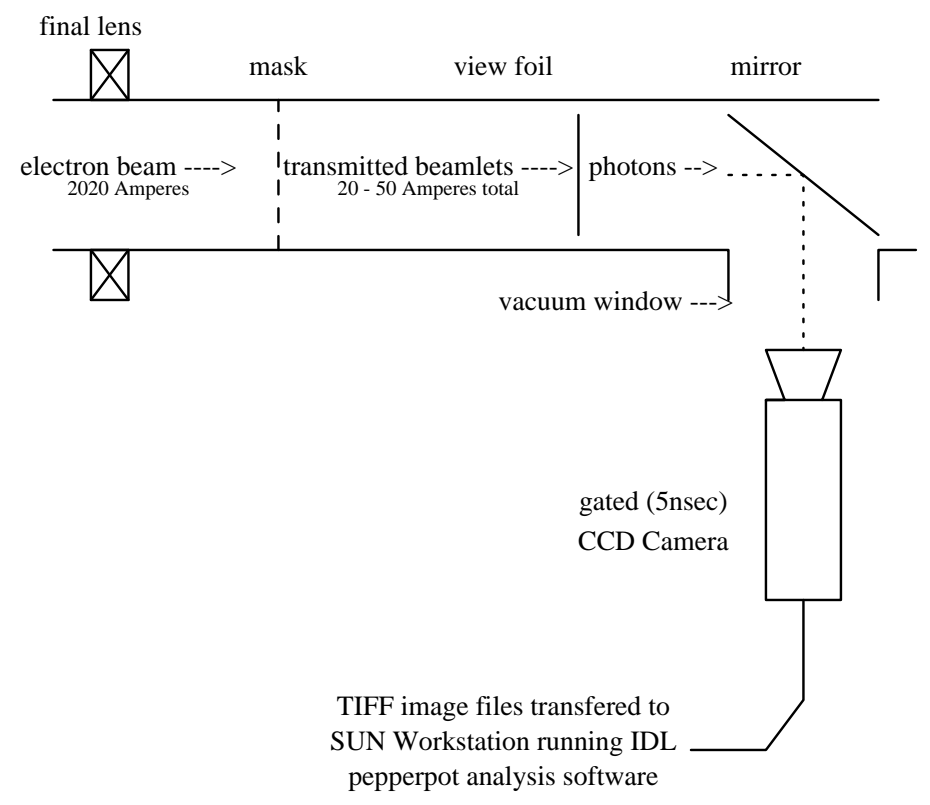

FIGURE 3. Major components of the pepper pot emittance diagnostic. A range thick mask, a phosphor viewing foil, mirror and gated CCD camera. 


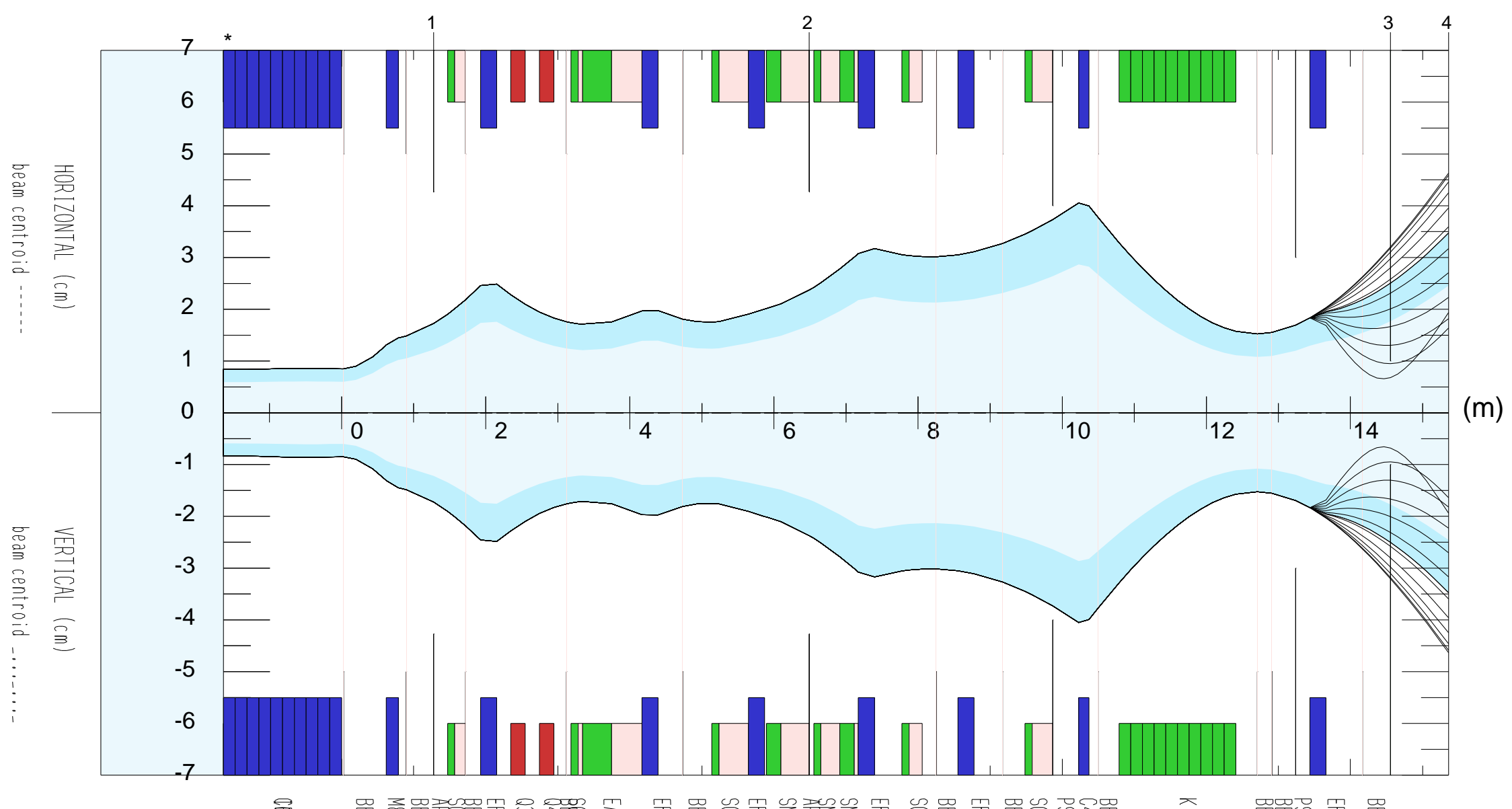

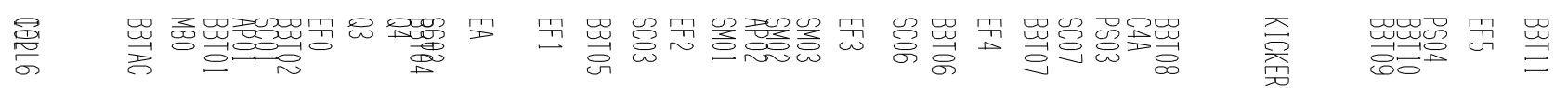

FIGURE 4

Beam profile calculated for the "New Tune" experimental magnet settings leading up to the emittance mask. The last focusing magnet EF5 is scanned in strength. 


\section{ETAll_PepperPot_Mask}

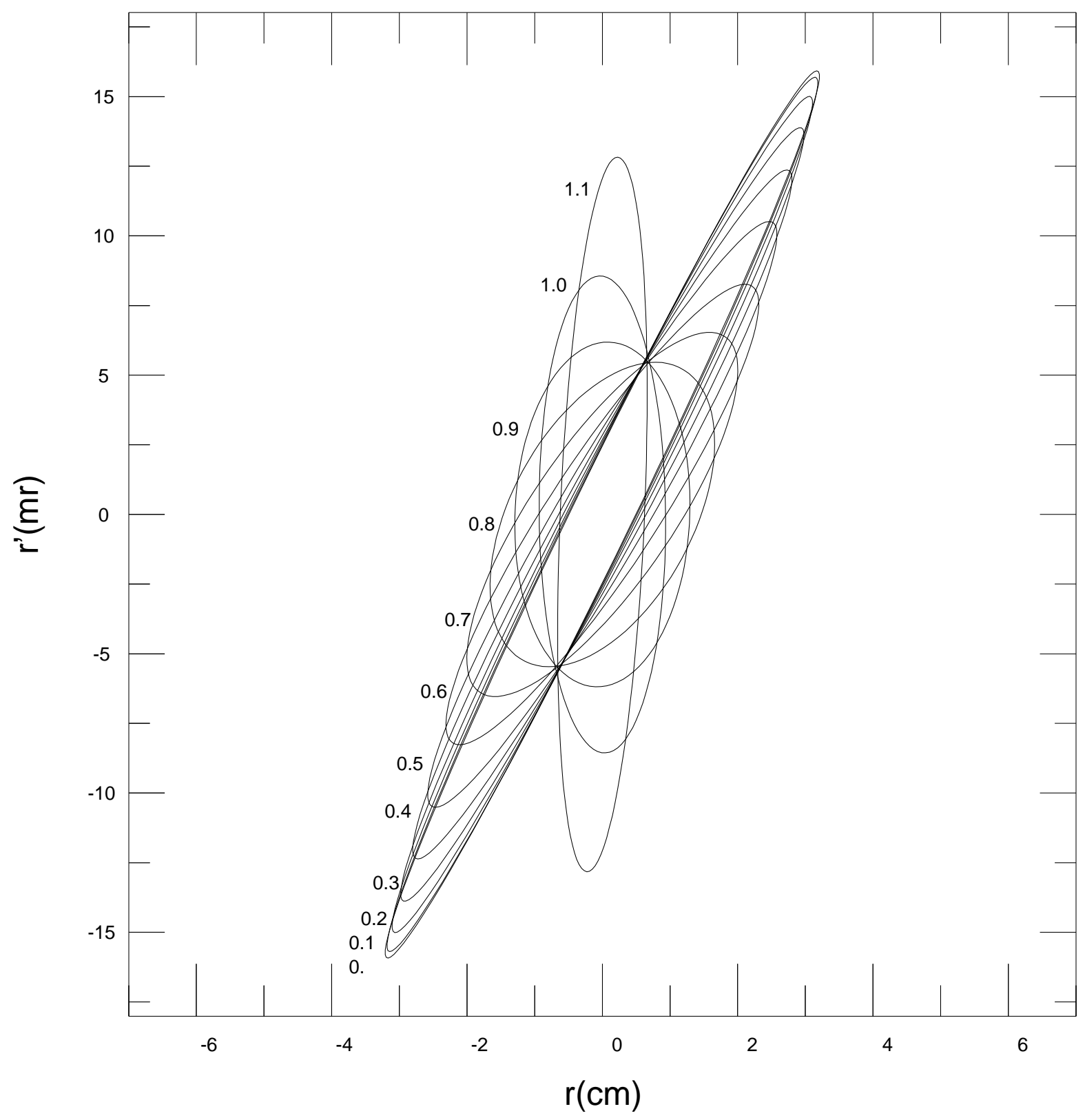

FIGURE 5

Phase space at the location of the emittance mask for the magnet settings of ETA day 8149 with EF5 scan in $0.1 \mathrm{kG}$ steps between zero and $1.1 \mathrm{kG}$. 


\section{ETAll_PepperPot_Mask}

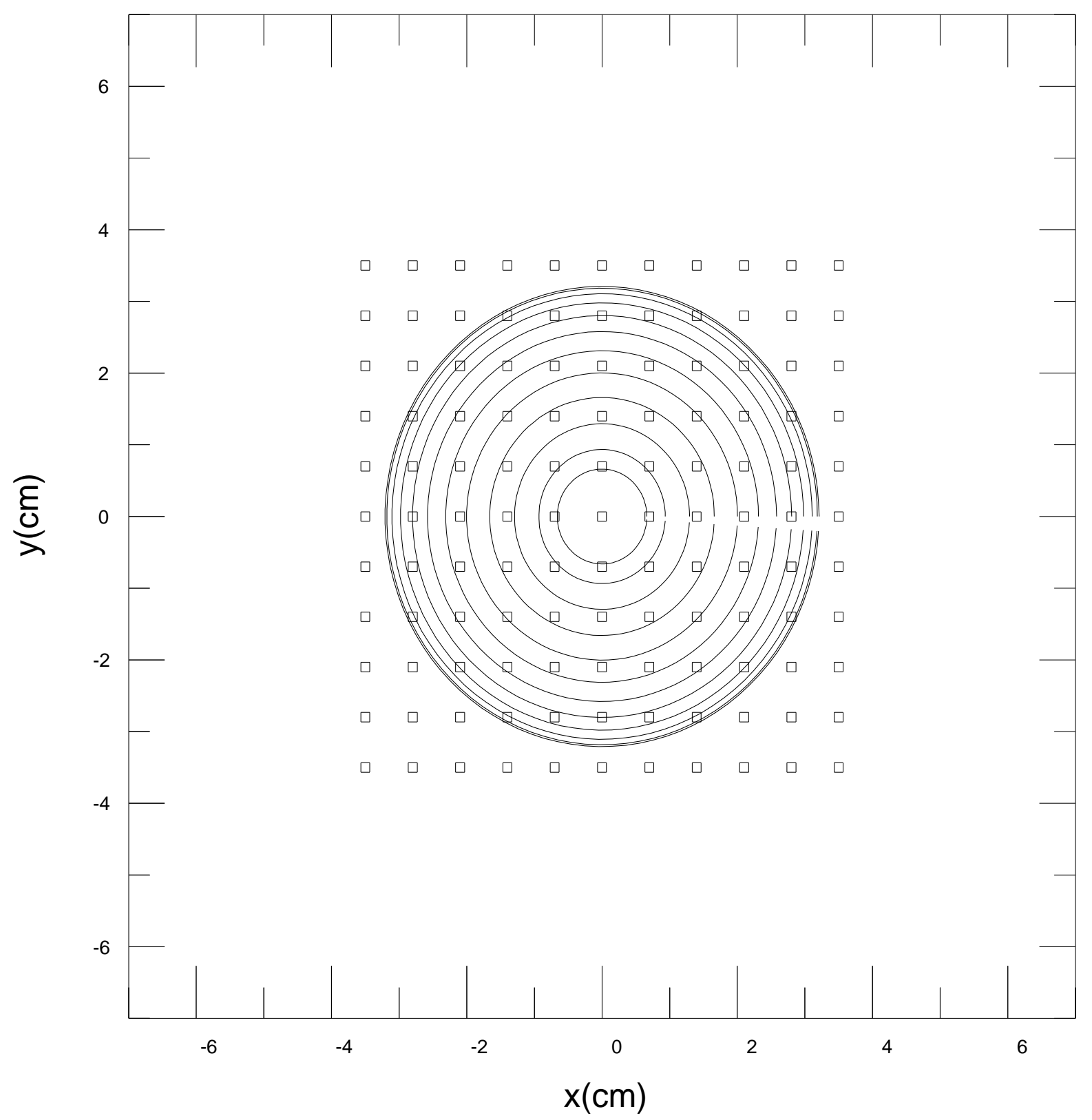

FIGURE 6

Calculated beam spot on the emittance mask for magnet settings used in figures 3 and 4 with the final lens EF5 scanned in $0.1 \mathrm{kG}$ steps. Hole radius is $0.0660 \mathrm{~cm}$ (\#55 drill) with angular acceptance of $+-35 \mathrm{mr}$. Hole spacing is $7.0 \mathrm{~mm}$ in 1.5 inch thick carbon. 


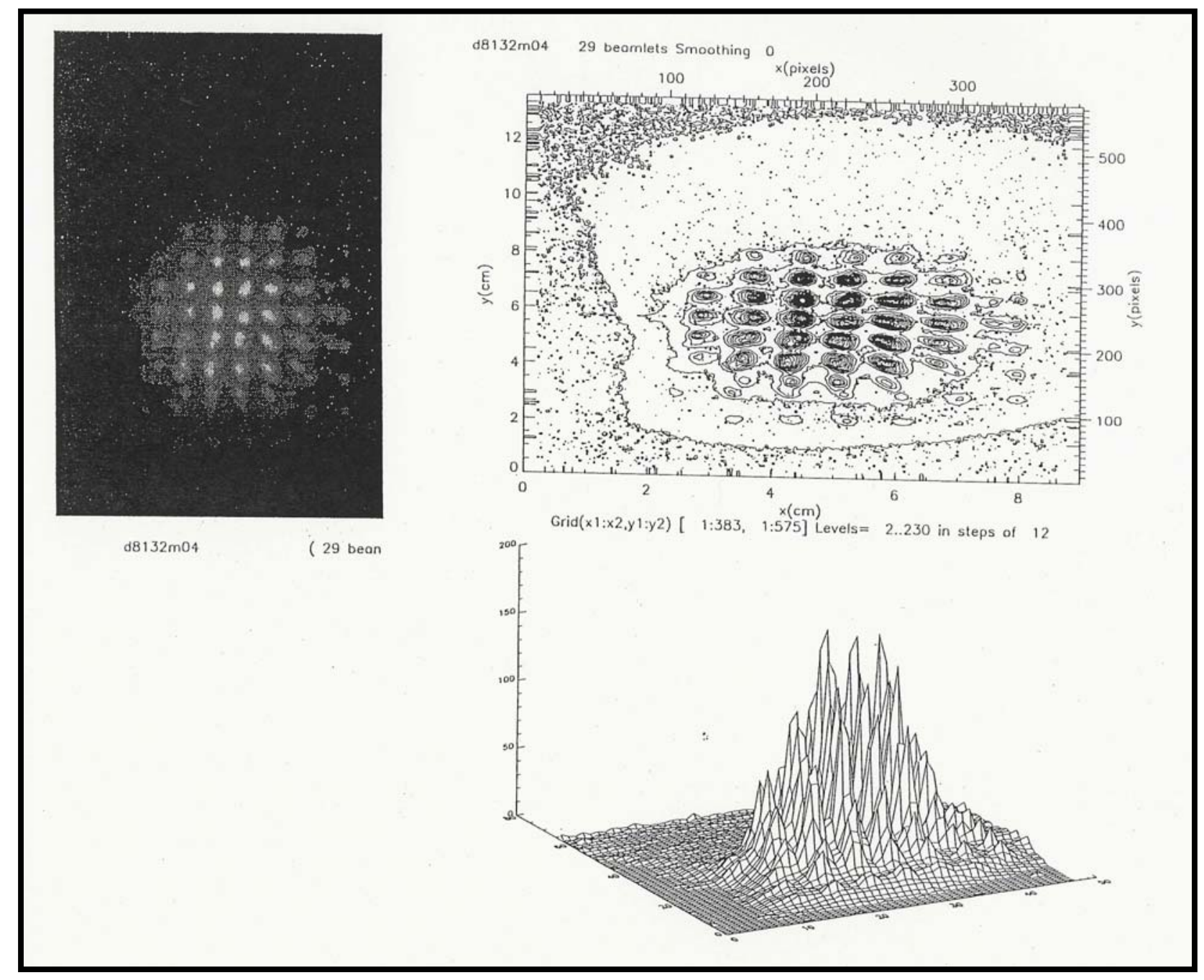

FIGURE 7

Typical emittance image for the "old tune" at nominal parameters of 6.0 MeV, 1800 Amperes. The $10 \mathrm{nsec}$ gated tv image, contour plot and surface plot for shot D8132M04. 


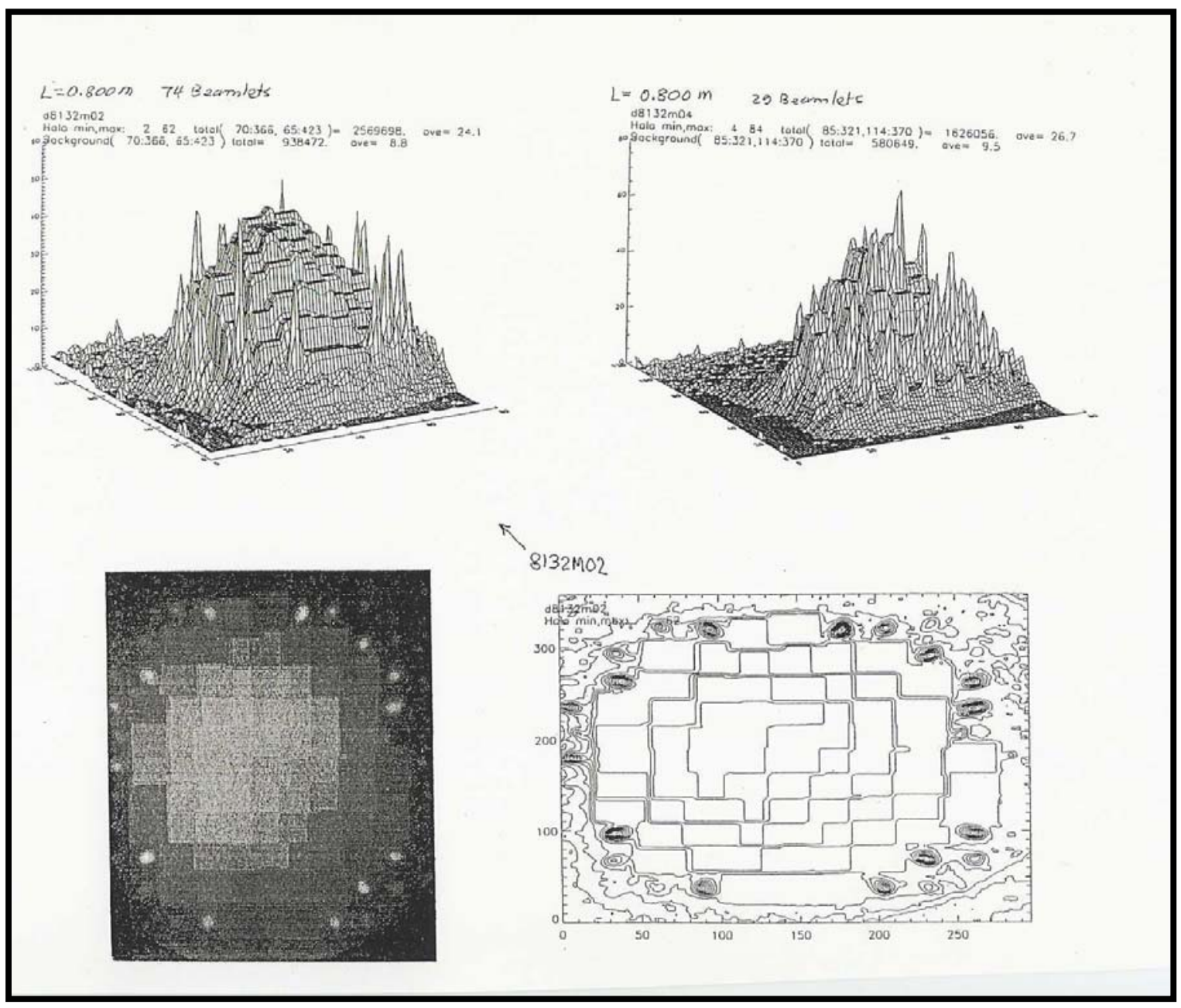

FIGURE 8

Shot D8132M04 with the 29 beamlets subtracted in software from the actual image. The result is the "pedestal". Also shown is shot D8132M02 with 74 beamlets subtracted. 


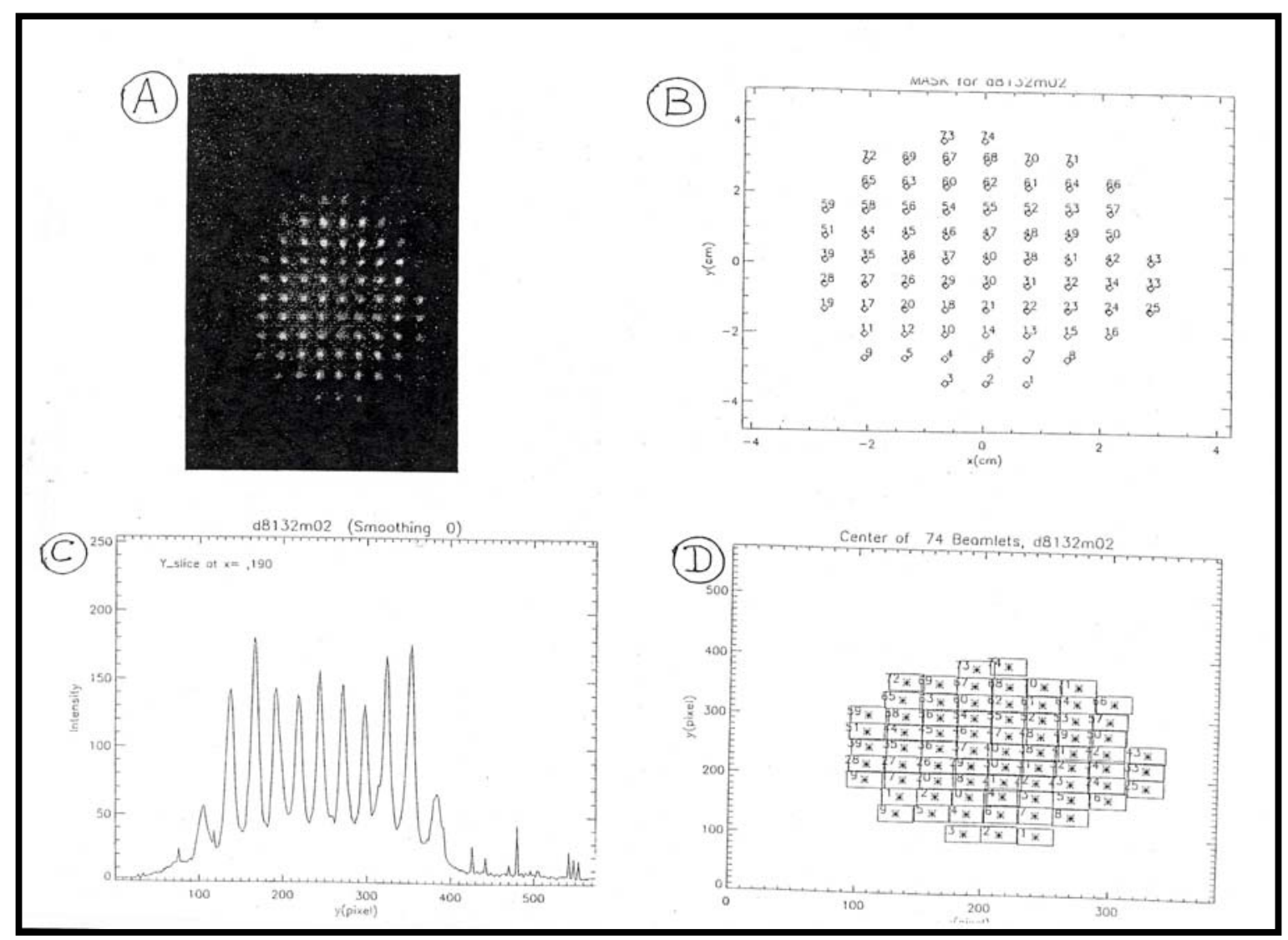

FIGURE 9

Typical image and beamlet mask used in the reconstruction of the beam emittance for the old tune. 

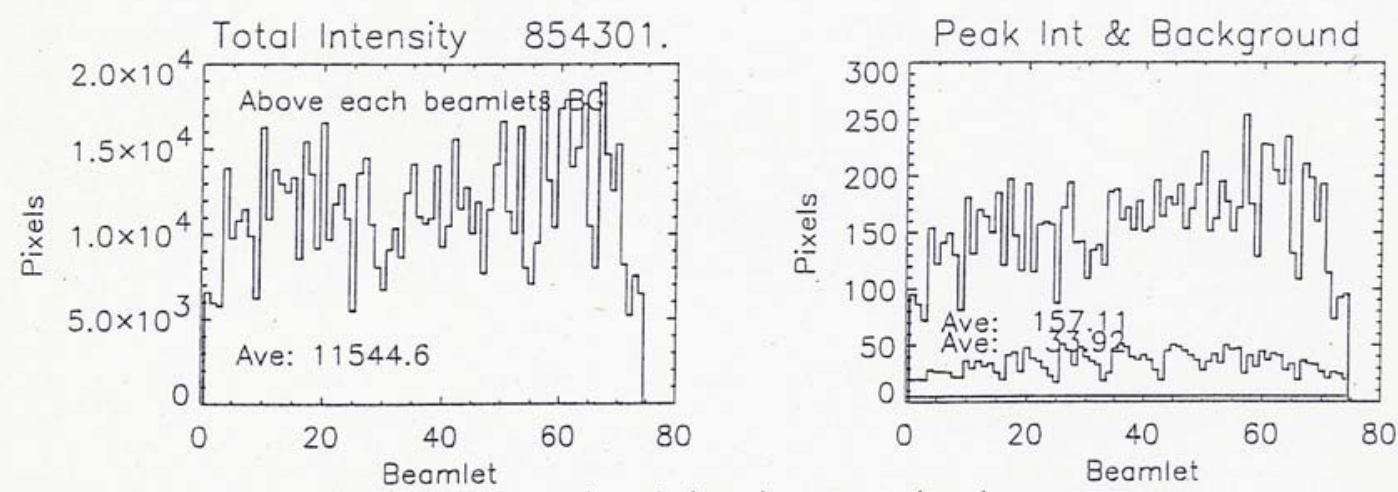

d8132m02 1000.00(22.912/74) (Amp), Beamlet Radius

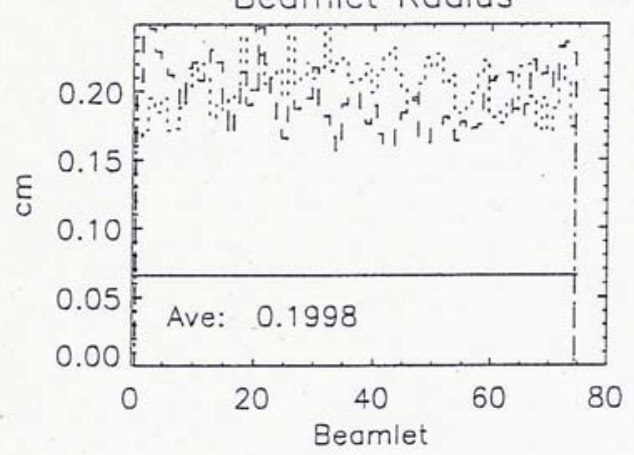

$6.100(\mathrm{MeV}), \quad 10 \%$ level
X,Y Angular Spread (max-min)
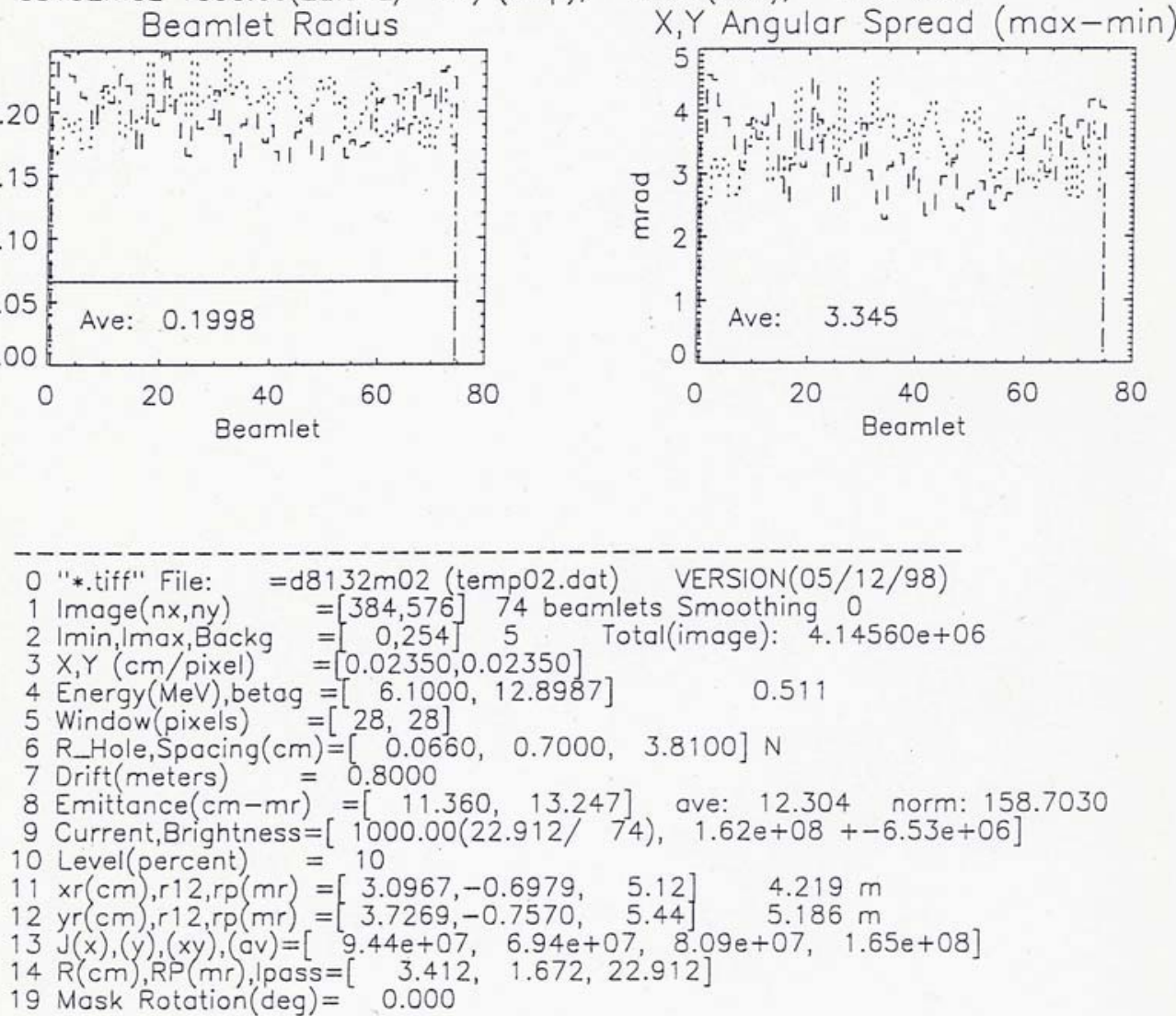

FIGURE 10

Old tune analysis for shot D8132M02. The beamlets expand from 0.066 $\mathrm{cm}$ to an average of $0.199 \mathrm{~cm}$ in the 0.8 meter drift. This gives an average angular value of $3.34 \mathrm{mr}$. 


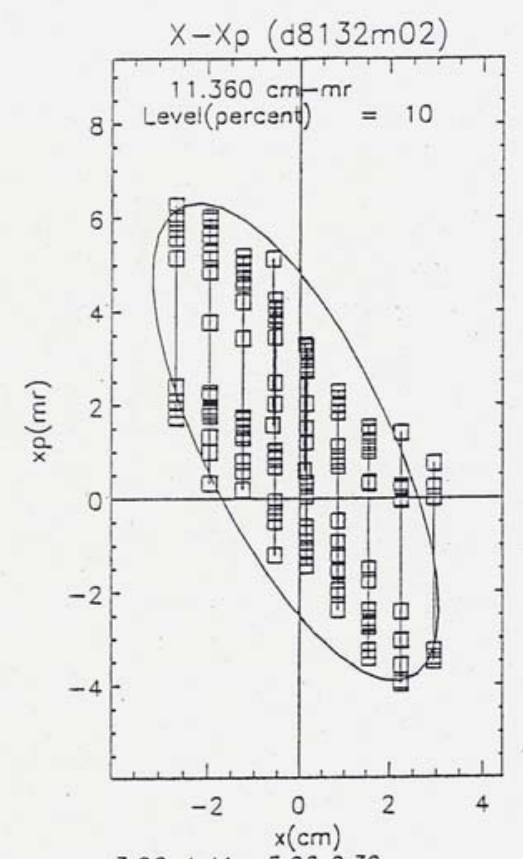

$\begin{array}{llll}-3.99 & 4.41 & -5.96 & 9.39\end{array}$

emittance $\quad 11.36 \mathrm{~cm}-\mathrm{mr}$

$x, r 12, x p=3.097-0.6979 \quad 5.122$

Level(percent) $=10$ at mask

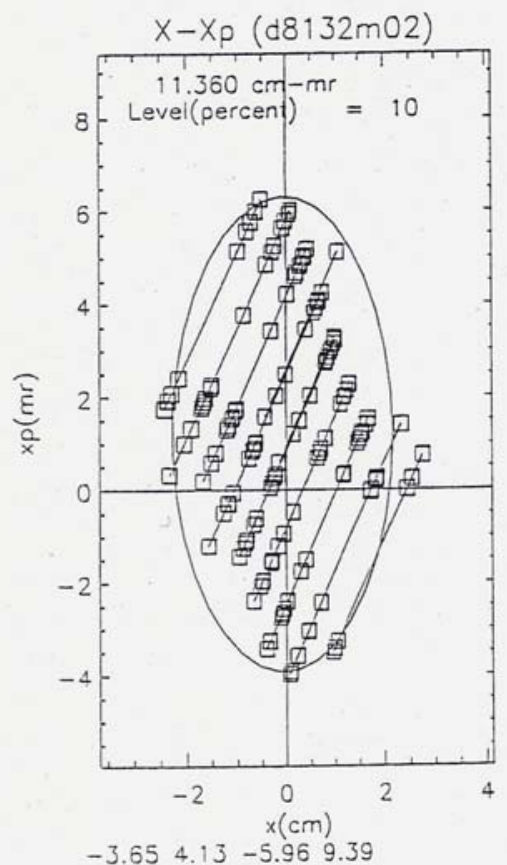

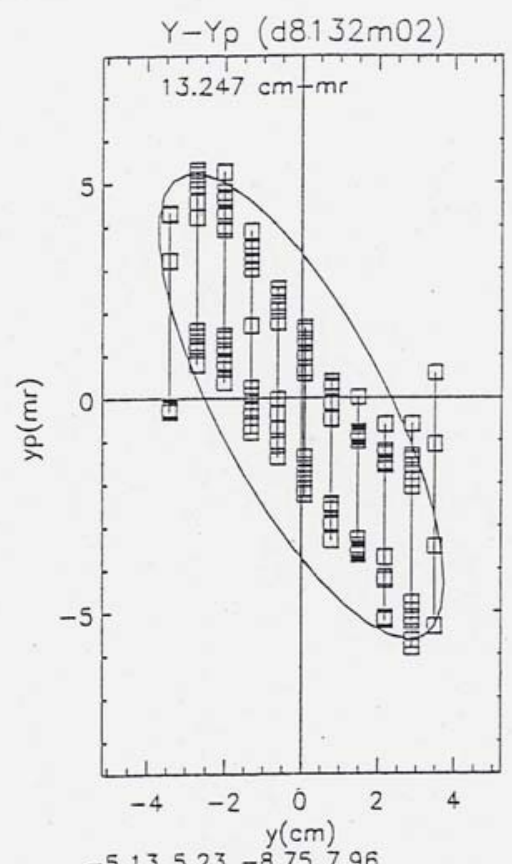

$-5.135 .23-8.757 .96$

emittance $\quad 13.25 \mathrm{~cm}-\mathrm{mr}$

$y, r 34, y p=3.727-0.7570 \quad 5.440$

74 beamiets Smoothing

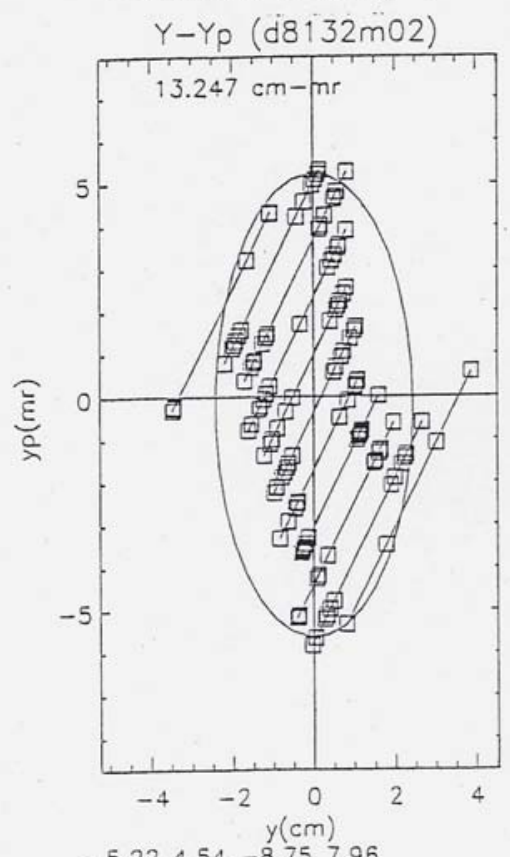

$-5.224 .54-8.757 .96$

FIGURE 11

Reconstructed old tune phase space at the location of the mask and transformed to the location of the waist. 


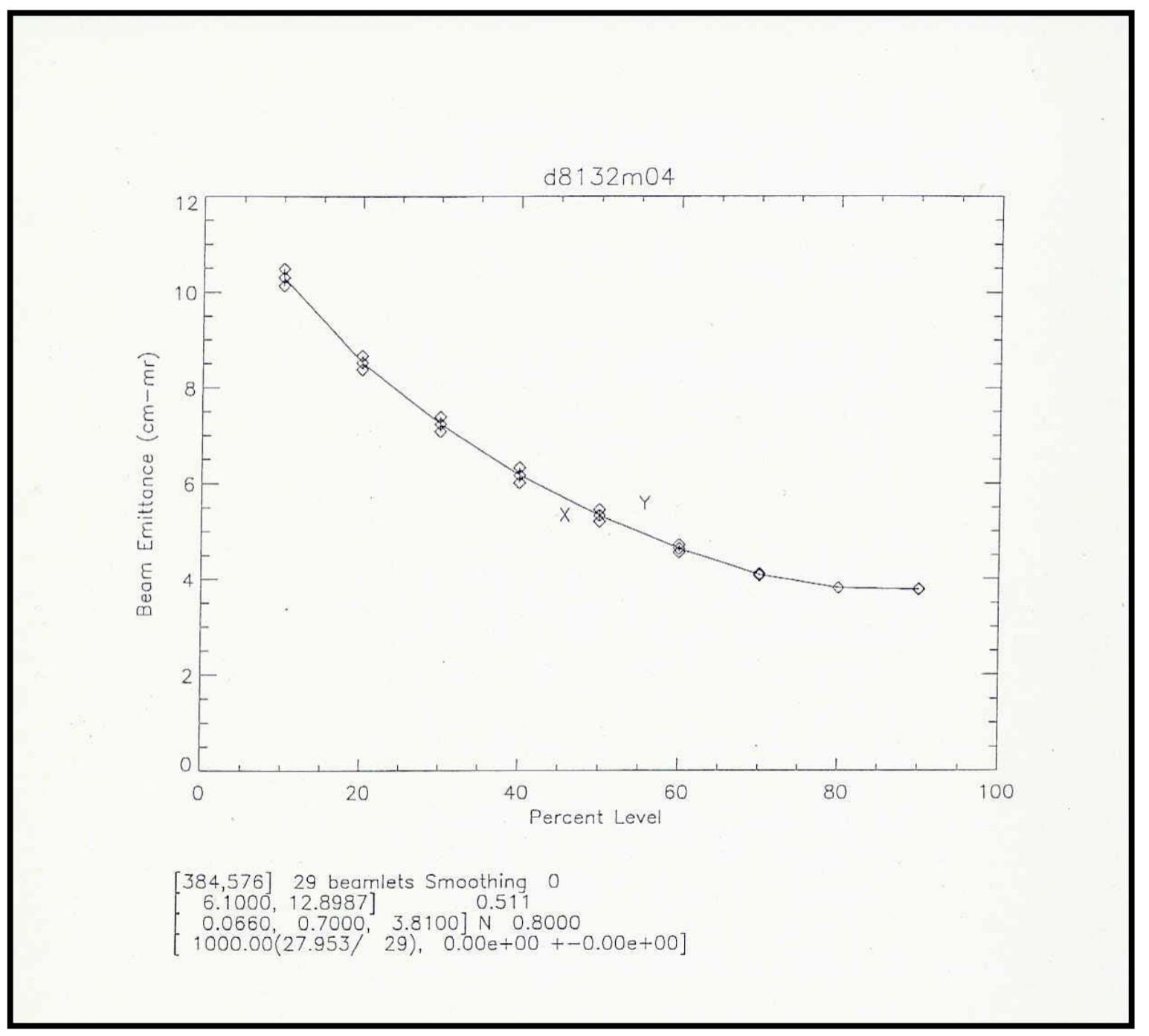

FIGURE 12

Reconstructed emittance vs amplitude. 


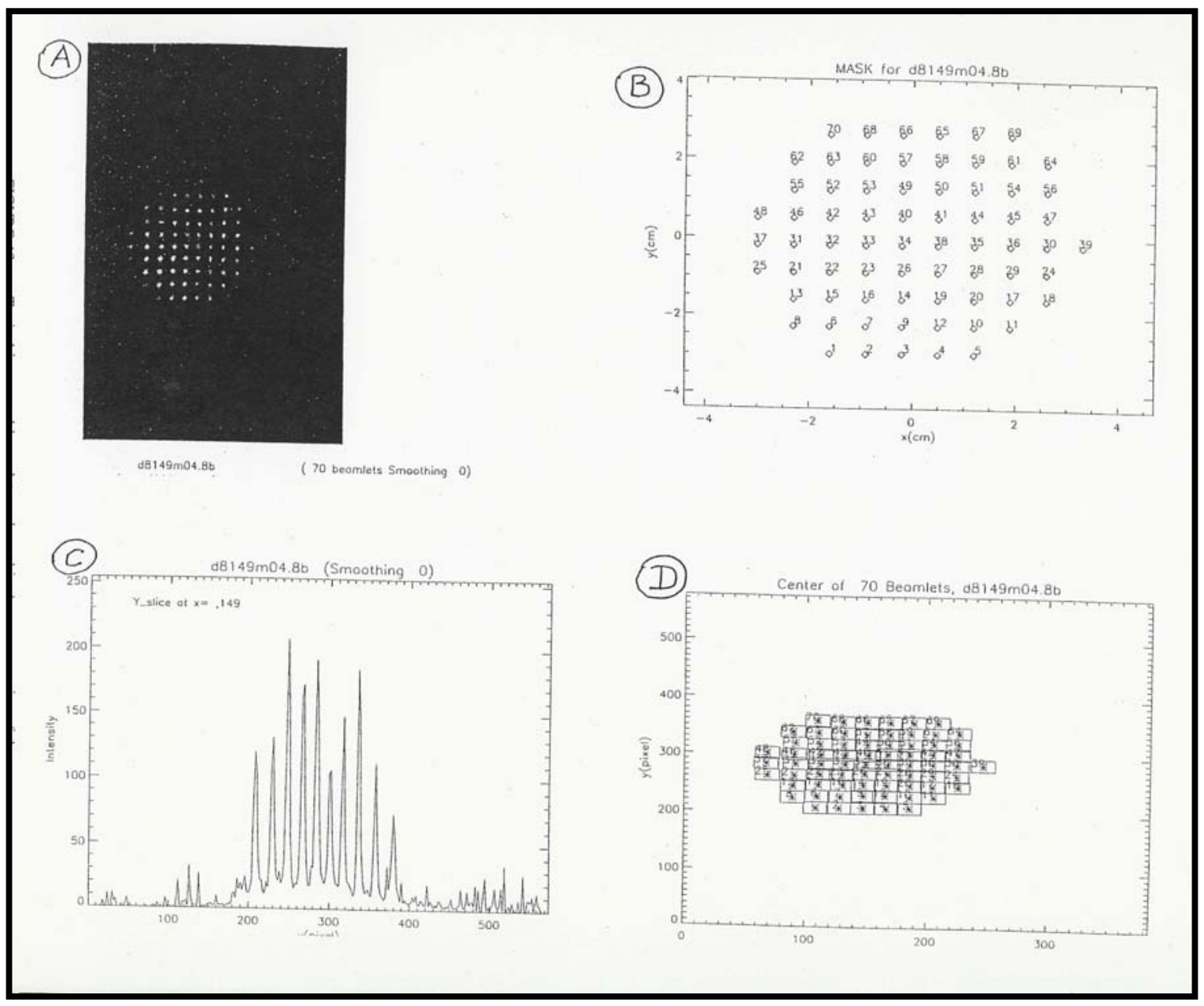

FIGURE 13

Typical image and beamlet mask used in the reconstrcution of the beam emittance for the new tune data. 

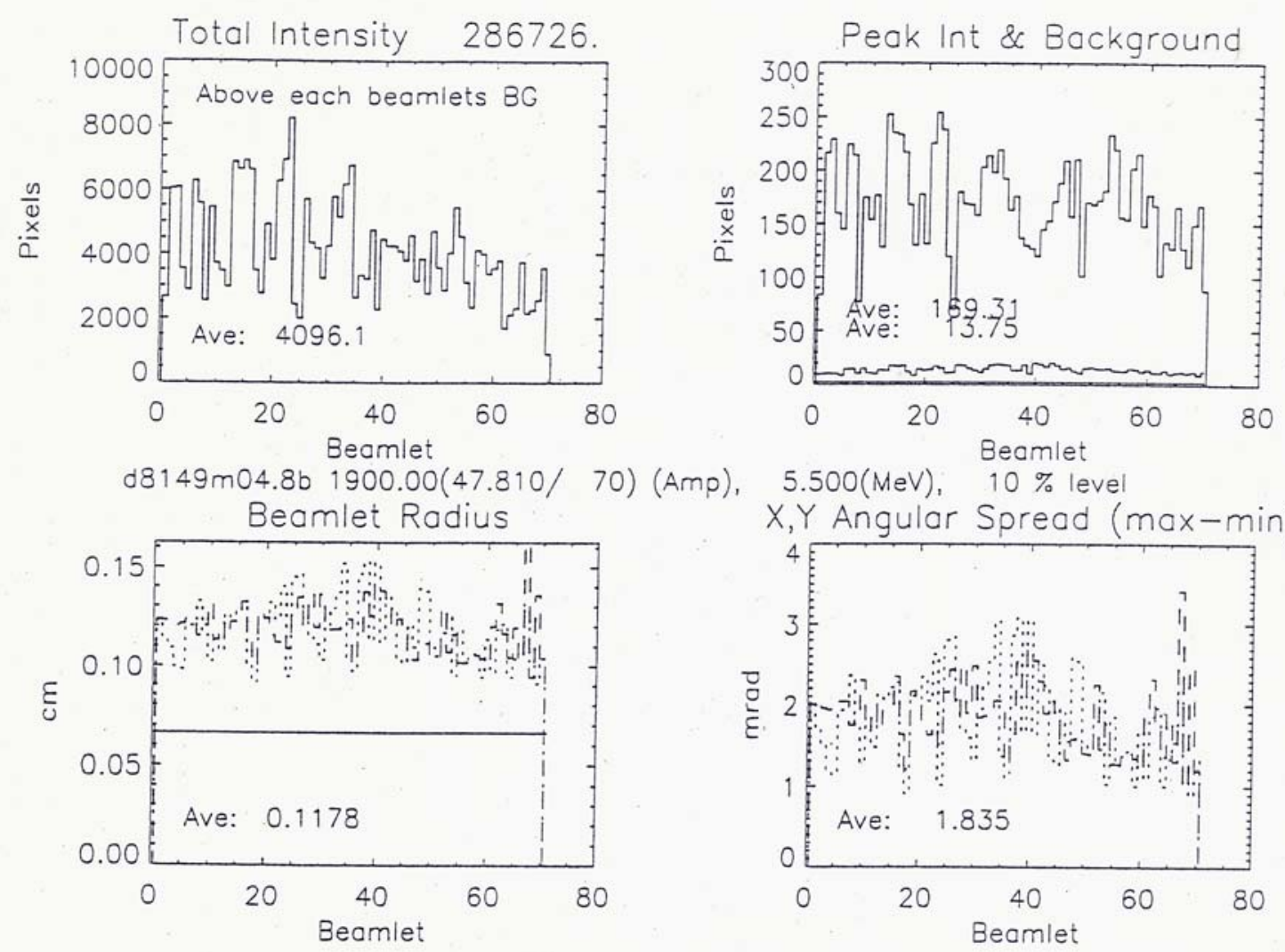

70) (Amp),

$5.500(\mathrm{MeV}), \quad 10 \%$ level

$X, Y$ Angular Spread (max-min)

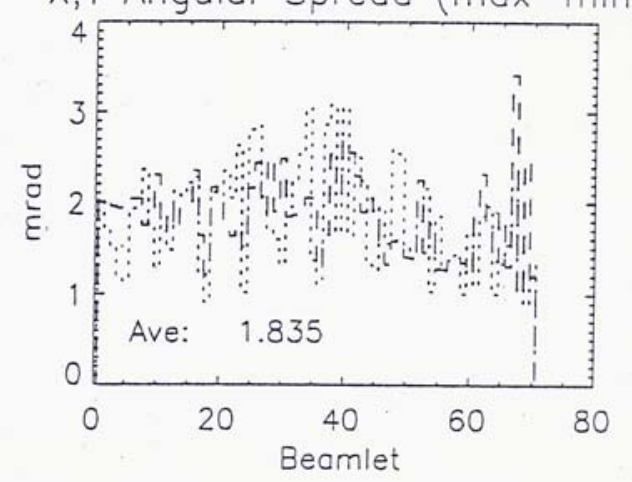

FIGURE 14

New tune analysis for shot D8149M04. The beamlets expand from 0.066 $\mathrm{cm}$ to an average of $0.118 \mathrm{~cm}$ in the 0.564 meter drift. This gives an average beam divergence of $1.83 \mathrm{mr}$. 


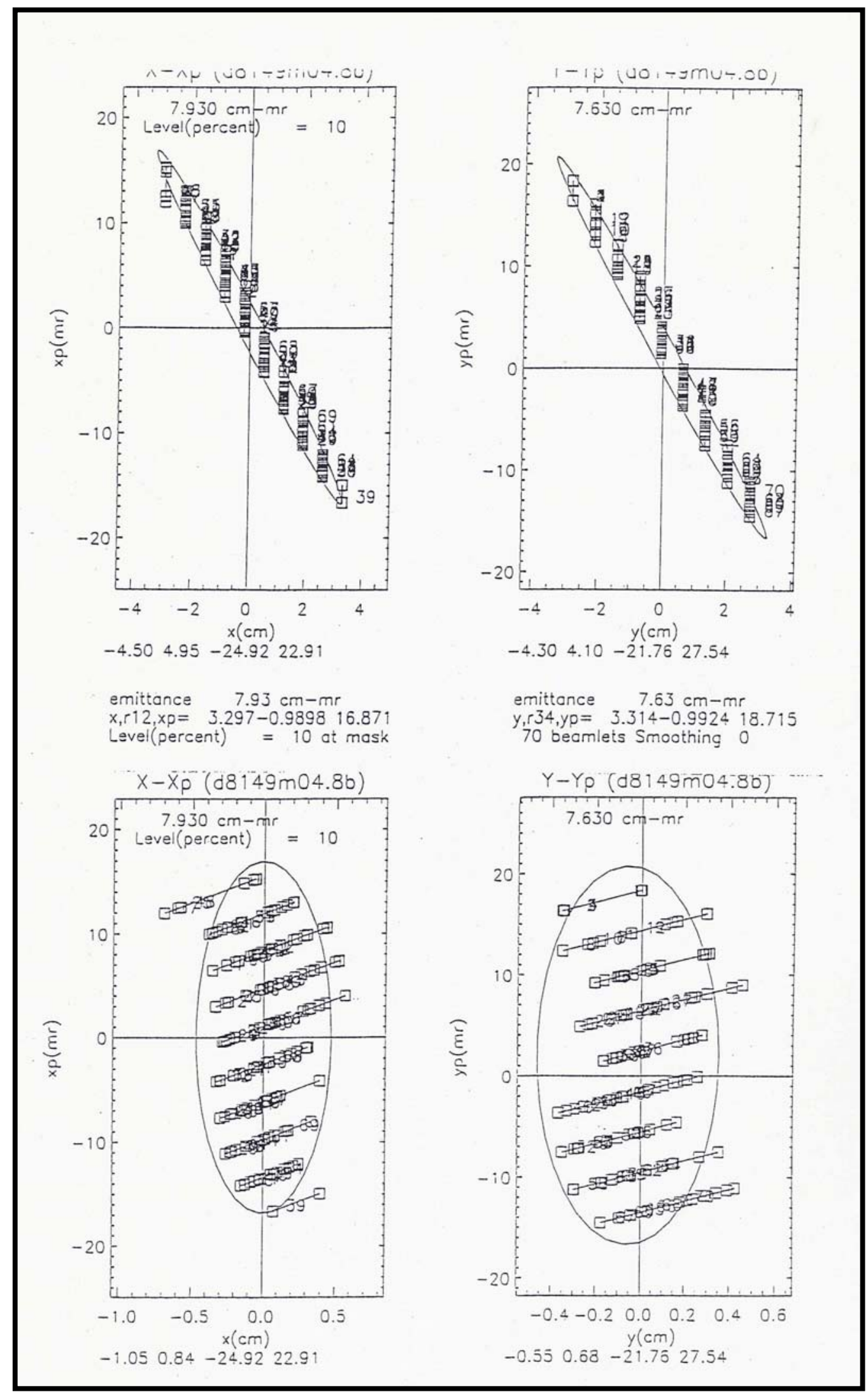

FIGURE 15

Reconstructed new tune phase space at the location of the mask and transformed to the location of the waist. 


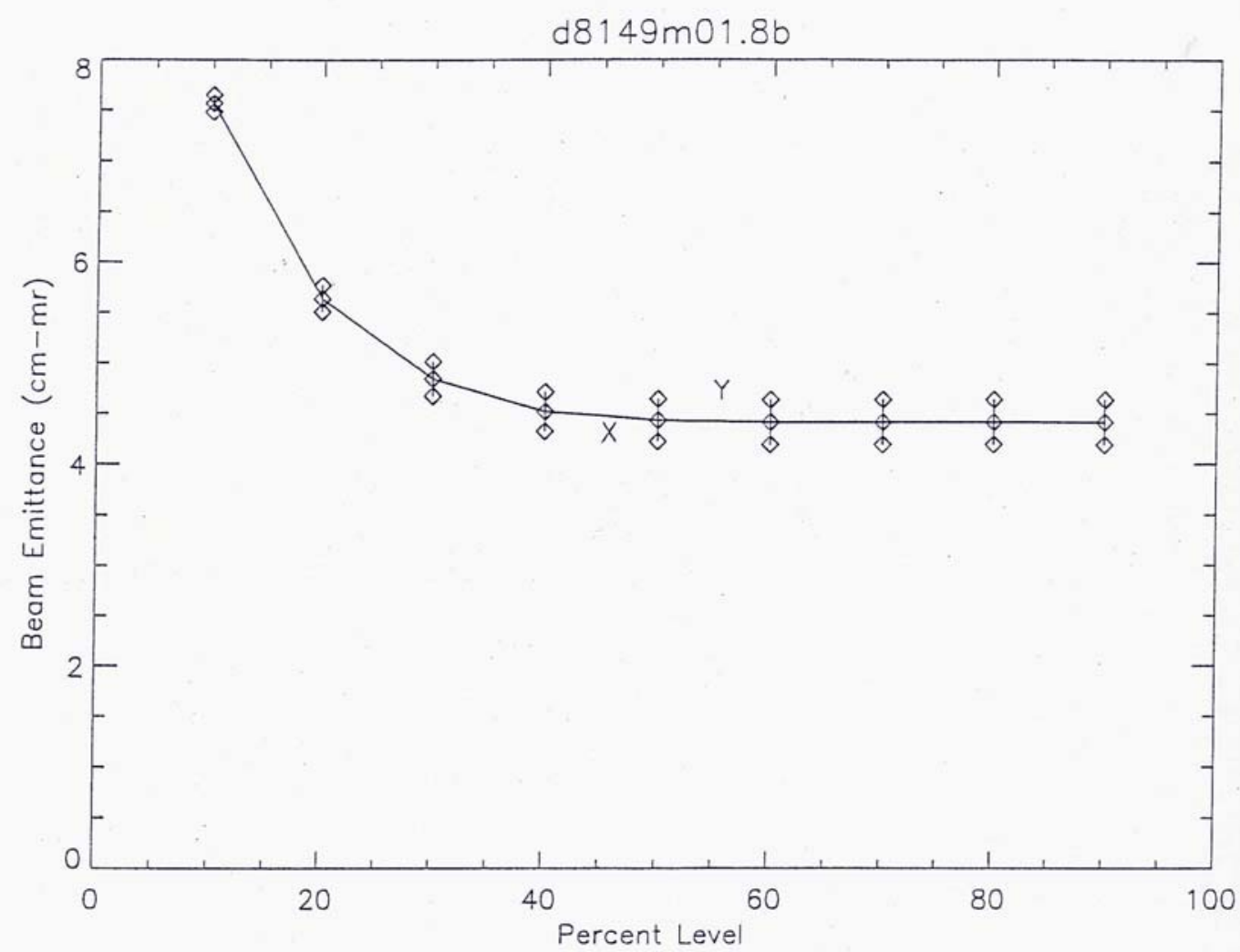

$\left[\begin{array}{c}384,576] 65 \text { beamlets Smoothing } 0 \\ 5.5000,11.7206] \\ 0.0660,0.7000, \quad 3.8100] \mathrm{N} 0.5640 \\ 1900.00(52.814 / 65), \quad 0.00 \mathrm{e}+00+-0.00 \mathrm{e}+00]\end{array}\right.$

FIGURE 16

Reconstructed emittance vs amplitude. The new tune emittance was sufficiently better than the old tune that the higher percent levels do not render an measure of the beamlet expansion. This will be remedied by increasing the distance between the mask and view foil. 


\section{NEW AND OLD TUNE}

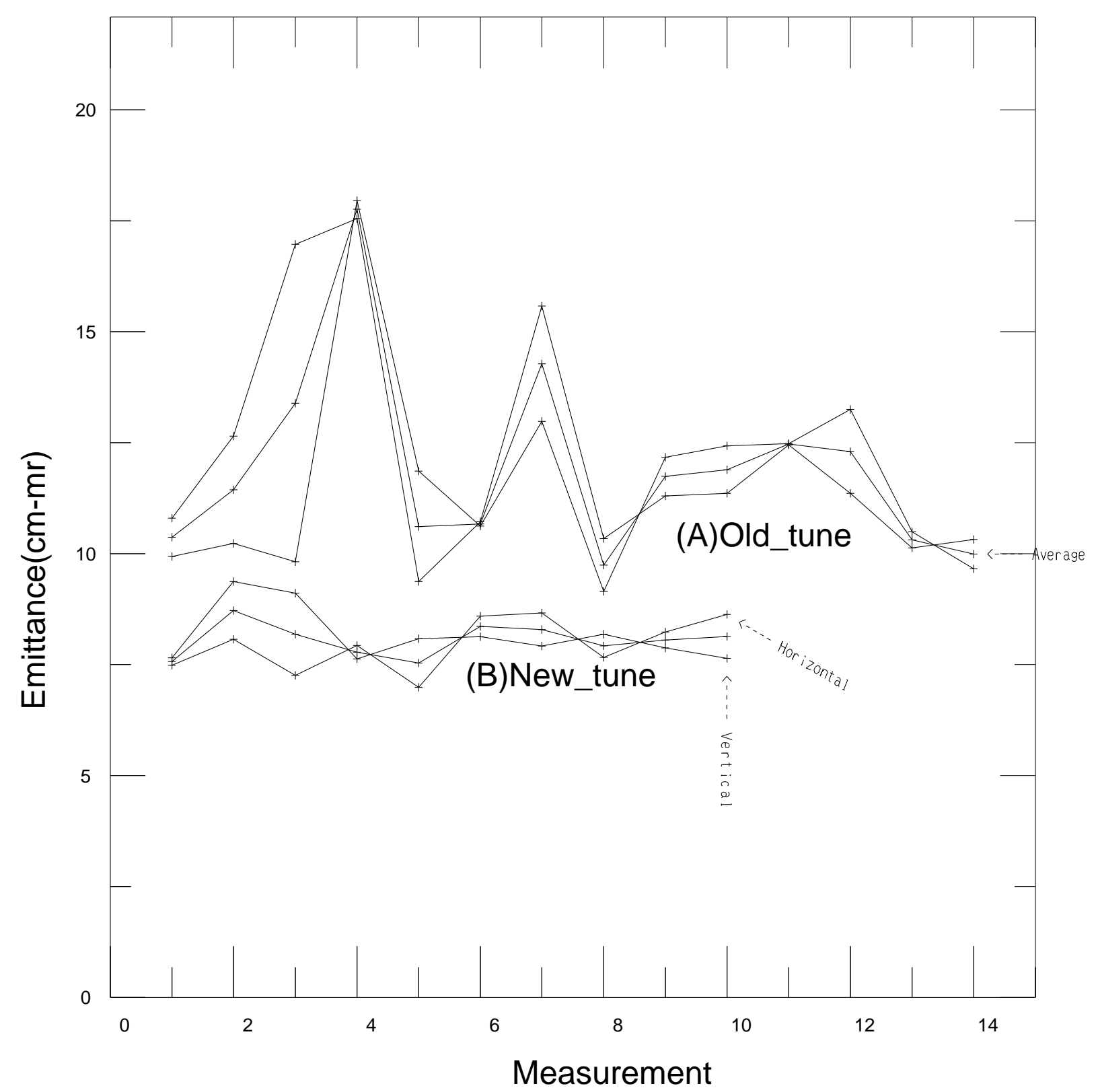

FIGURE 17

Comparison between the various measurements of the old and new tunes. ETAll $5.50 \mathrm{MeV}$ run at 2020 Amperes (Data files d8147m01 etc.)

[A] Old tune, average emittance $11.9+-2.0 \mathrm{~cm}-\mathrm{mr}$.

[B] New tune, average emittance $8.05+-0.53 \mathrm{~cm}-\mathrm{mr}$. 
NEW TUNE ETAII 5.5 MeV, 2020 Amperes, Emittance $8.0 \mathrm{~cm}-\mathrm{mr}$ Normal -5.0 Amperes: D8149M14.8b

Normal Coil setting: D8149M15.8b

Normal +5.0 Amperes: D8149M16.8b

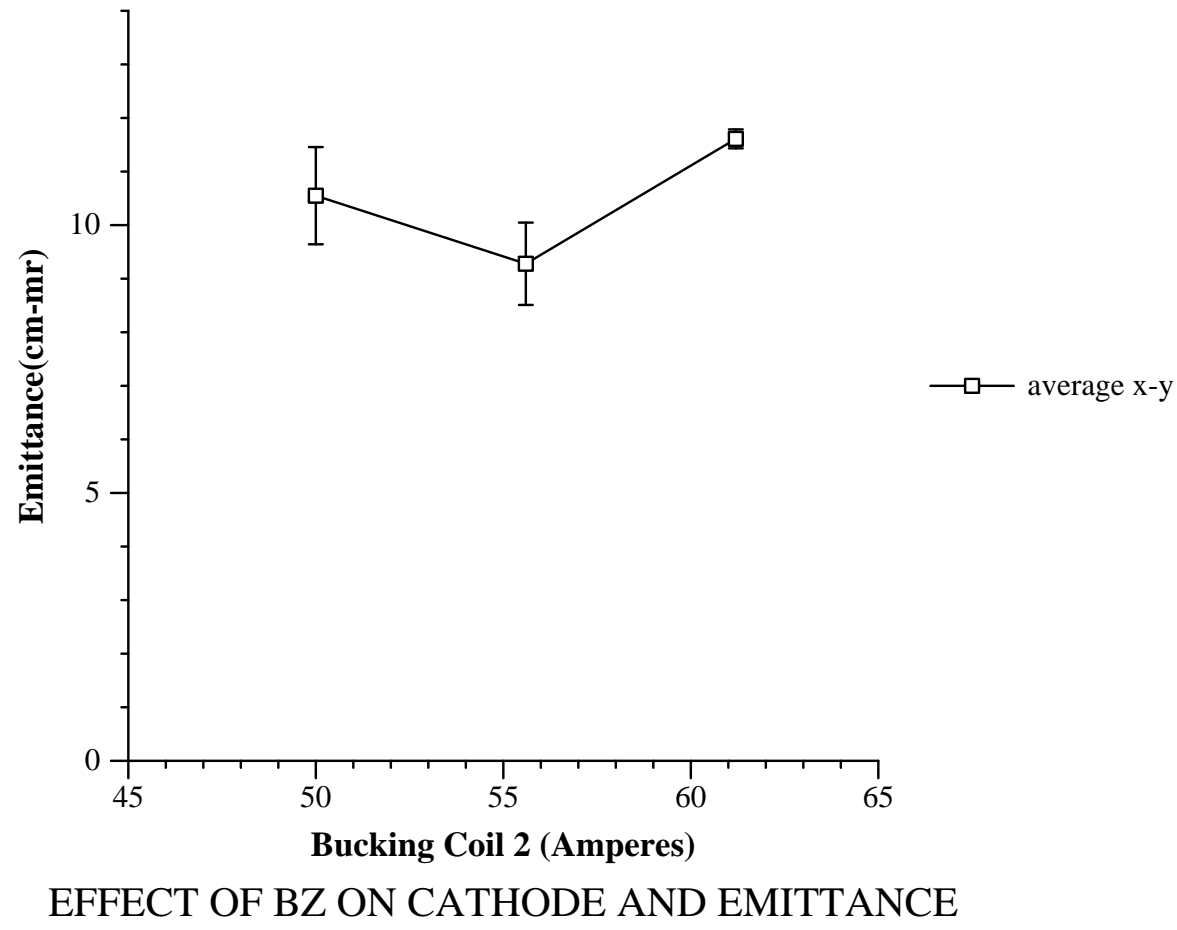

\$WRK/eta/reports/text.60cell_emit

6/04/98 A.C.Paul 